\title{
LA INTRODUCCIÓN EN ESPAÑA DE LA LIMITACIÓN DE MANDATOS: UNA APROXIMACIÓN CRÍTICA
}

CARLOS FLORES JUBERÍAS

Y JORGE GARCÍA-CONTELL MUÑOZ 
SUMARIO

1. ALGUNAS CONSIDERACIONES EN TORNO A LA ACTUALIDAD DEL DEBATE EN ESPAÑA. 2. LA CAMBIANTE ACOGIDA DE LA LIMITACIÓN DE MANDATOS EN EL CONSTITUCIONALISMO COMPARADO. 3. ¿SERÍA ÚTIL INTRODUCIR LA LIMITACIÓN DE MANDATOS EN ESPAÑA? 4. ¿SERÍA CONSTITUCIONAL INTRODUCIR LA LIMITACIÓN DE MANDATOS EN ESPAÑA? 5. CONCLUSIONES 


\title{
LA INTRODUCCIÓN EN ESPAÑA DE LA LIMITACIÓN DE MANDATOS: UNA APROXIMACIÓN CRÍTICA
}

\author{
CARLOS FLORES JUBERÍAS* \\ (Catedrático acr. de Derecho Constitucional, Universidad de Valencia) \\ JORGE GARCÍA-CONTELL MUÑOZ \\ (Abogado, Ilustre Colegio de Abogados de Valencia)
}

\section{ALGUNAS CONSIDERACIONES EN TORNO A LA ACTUALIDAD DEL DEBATE EN ESPAÑA}

Como es sabido, la Constitución española no contiene previsión alguna respecto a lo que coloquialmente conocemos ya como «la limitación de mandatos»; y que cabría definir como la posibilidad de que por medio de una norma jurídica se limite el número de veces que un cargo público de elección popular — bien sea del ejecutivo bien sea del legislativo_- pueda resultar elegido; o el número de mandatos completos, o de parte de ellos, o de años, durante los que pueda ejercer como tal. Quizás por ello, tampoco hasta hoy ha considerado oportuno el legislador introducir en nuestro ordenamiento jurídico estatal este tipo de restricciones, de manera que ni en la Ley Orgánica 5/1985 del Régimen Electoral General —reformada de manera reiterada a lo largo de los años y de forma sustantiva en 2011 — ni en la Ley 50/1997 del Gobierno, se contienen provisiones de este tipo, ni tampoco las contemplan los reglamentos del Congreso o el Senado. La ausencia en nuestro ordenamiento jurídico estatal de este tipo de previsiones supone implícitamente la indefinida reelegibilidad de los miembros de las Cortes y del Presidente del Gobierno, cosa que por otra parte ha sido una

* Dirección de contacto: Departamento de Derecho Constitucional y Ciencia Política. Facultad de Derecho. Avenida de los Naranjos, s/n. 46071 Valencia. Tel.: (34) 963828587. Fax: (34) 963828119. E-mail: carlos.flores@uv.es 
constante a lo largo de nuestra historia constitucional desde los ya lejanos tiempos en los que el artículo 110 de la Constitución gaditana prescribiera —infructuosamente- que «Los diputados no podrán volver a ser elegidos, sino mediante otra diputación».

No obstante lo anterior, algo parece estar cambiando. La crisis financiera de la pasada década, que con tanta dureza golpeó con la economía española y tan radicalmente desvaneció el espejismo de un crecimiento indefinido, y los devastadores efectos de ésta sobre las políticas sociales constitutivas del llamado Estado de bienestar, puso fin a la relativa indiferencia con la que desde algunos sectores se habían venido contemplando algunas de las prácticas más éticamente reprobables de nuestra clase política —el enriquecimiento ilícito, el tráfico de influencias, la colusión de intereses con los agentes económicos- inaugurando un nuevo periodo en el que la aspiración a terminar con sus privilegios más arraigados pasó a situarse entre las más serias preocupaciones de los españoles ${ }^{1}$. A mediados de 2011 los Barómetros del CIS $^{2}$ revelaban ya que junto con el desempleo y la economía, los españoles habían empezado a contemplar a la clase política como una de sus más serias fuentes de preocupación, y ello hasta extremos que no se habían visto en la España constitucional ni siquiera durante los años más broncos de la disputa González-Aznar ${ }^{3}$. Consecuencia de ello serían, a no mucho tardar, las movilizaciones que llevaron y siguieron al llamado 15-M, y poco más tarde la emergencia de las fuerzas políticas de nuevo cuño que a la postre alcanzarían representación parlamentaria, erosionando seriamente la de los partidos tradicionales, tras las elecciones generales de 2015 y 2016.

Pues bien: a medida que esta sensación de malestar frente a la clase política se fue generalizado entre el cuerpo político, comenzó a extenderse igualmente la exigencia de la adopción de medidas drásticas encaminadas de una parte a expulsar de la vida pública — y en especial de las instituciones - a los elementos corruptos de la clase política y de otra a evitar que escándalos similares se repitieran en el futuro. Y es llegados precisamente a este punto cuando han empezado a cobrar carta de naturaleza en el debate político español las posiciones favorables a la inclusión en nuestro ordenamiento jurídico de limitaciones

1 Villoria Mendieta, M. y Jiménez, F., «La corrupción en España (2004-2010): datos, percepción y efectos», REIS-Revista Española de Investigaciones Sociológicas n. o 138 (2012), pp. 109-134.

2 Centro de Investigaciones Sociológicas, «Estudio n. ${ }^{\circ}$ 2.909, Barómetro de julio de 2011», en línea en http:/www.cis.es/cis/opencms/-Archivos/Marginales/2900_2919/2909/ Es2909.pdf (aquí, y en adelante, fecha de consulta: 21.07.2017).

3 Gómez-CotTA, C., «La clase política, entre las mayores preocupaciones de los españoles», en Ethic. La vanguardia de la sostenibilidad, en línea en http://ethic.es/2011/06/la-clase-politicaentre-las-mayores-preocupaciones-de-los-espanoles/ 
expresas a la reelección de los cargos públicos y, en concreto, de la Presidencia del Gobierno y de los ejecutivos autonómicos, y con algo menos de relevancia también en las cámaras legislativas de uno y otro nivel, por entender como evidente la existencia de una relación de causa-efecto entre el enquistamiento de las elites políticas en los puestos mas decisivos de las instituciones ejecutivas y legislativas y el surgimiento de redes clientelares y prácticas corruptas en el seno y en los aledaños del poder.

Más allá de la creciente presencia del tema en el debate social ${ }^{4}$, la cuestión de la limitación de mandatos ha ido también penetrando de manera gradual en el terreno del debate partidista e incluso perfilándose como una opción normativa a considerar. Probablemente la más relevante prueba de ello se halle en el pacto de gobierno sellado entre el Partido Popular y Ciudadanos en agosto de 2016, a fin de hacer posible la investidura de Mariano Rajoy ${ }^{5}$, entre cuyas medidas se quiso incluir la de tasar el mandato de los presidentes del Gobierno a un máximo de dos legislaturas, proponiendo textualmente:

«96. Establecer el compromiso de que quien haya ostentado durante ocho años consecutivos el cargo de Presidente del Gobierno no opte a la reelección. En el seno del Pacto de Estado por la Regeneración y la Calidad de la Democracia, se procurarán las fórmulas precisas para regular este compromiso.»

Aunque a día de hoy dicho compromiso sigue circunscrito al campo de las propuestas programáticas, en otros contextos la idea de la limitación de mandatos sí que ha llegado a plantearse, e incluso a materializarse normativamente. Castilla-La Mancha se convirtió en la pionera a este respecto al aprobar la Ley $7 / 1997$, de 5 de septiembre, del Gobierno y del Consejo Consultivo ${ }^{6}$, cuyo artículo 4.2 preceptuaba que «No podrá ser elegido Presidente de la Junta de Comunidades quien ya hubiese ostentado este cargo durante al menos ocho años, salvo que hayan pasado cuatro años desde la terminación de su mandato», esta-

4 De la que, sin ánimo de exhaustividad, pueden dar cuenta los posicionamientos de RoDRÍGUEZ IbarRA, J. C., «Limitación de mandatos: ¿constitucional?», en El Confidencial de 13.06.2015; Galindo, J., «¿Limitar mandatos?», en El País de 12.08.2016; Vilches, J., «Limitar mandatos: la Ley de Hierro de Ciudadanos», en El Español de 16.08.2016; García Fernández, J., «La limitación del mandato del Presidente del Gobierno», en Sistema Digital de 02.01.2017 Ansón, L. M., «Limitación de mandatos», en El Mundo de 02.03.2017, o, en fecha un tanto más temprana, Flores Juberías, C., «A vueltas con la limitación de mandatos», ABC de 03.01.2008.

5 «150 Compromisos para mejorar España», disponible on-line en http://www.gppopular. es/documento-del-pacto-partido-popular-ciudadanos-150-compromisos-mejorar-espana/

${ }^{6}$ BOE n. ${ }^{\circ} 249$ de 17.10.1997. Aunque esta norma fue reformada por la Ley $11 / 2003$, de 25 de septiembre, del Gobierno y del Consejo Consultivo de Castilla-La Mancha (BOE n. ${ }^{\circ}$ 202, de 23.08.2000), la referida cláusula se mantuvo con idéntica formulación. 
bleciendo así el límite de una sola reelección consecutiva, aunque permitiendo las reelecciones alternas. Aunque la norma venía justificada —o al menos, hallaba su más cabal explicación - en el hecho de que por aquellas fechas su Presidente autonómico, el socialista José Bono, llevara ya catorce años en el cargo, lo cierto es que su alcance quedaría limitado ab initio por lo dicho en el dictamen del Consejo Consultivo autonómico, según el cual la limitación no afectaría a quien se hallare ostentando la Presidencia de la Comunidad en el momento de la promulgación de la ley, puesto que ello supondría dotar de efecto retroactivo a «una norma restrictiva del derecho a acceder en condiciones de igualdad a los cargos públicos, previsto en el artículo 23.2 de la Constitución» ${ }^{7}$.

En Cataluña una iniciativa de este orden fue introducida en la norma institucional básica de la Comunidad mediante la Ley Orgánica 6/2006, de 19 de julio, de reforma del Estatuto de Autonomía, cuyo artículo 67.2 afirma desde entonces que «El Presidente o Presidenta de la Generalitat es elegido por el Parlamento de entre sus miembros. Puede regularse por ley la limitación de mandatos ${ }^{8}$. De esta sumarísima regulación, tres datos merecen destacarse, acaso con la misma concisión: el primero sería la notoria timidez del Estatut catalán, que se contentó con plantear la limitación de mandatos como una mera hipótesis de futuro, y a circunscribirla a la más alta representación de la Comunidad; el segundo sería su absoluta intrascendencia durante el complejo proceso de elaboración, debate y fiscalización del Estatut, durante el que pasó por entero desapercibida sin que ni el Consell Consultiu de la Generalitat, ni la Comisión Constitucional del Congreso, ni el Tribunal Constitucional decidieran detenerse en ella; y el tercero sería, su práctica irrelevancia, ya que a pesar de estar prevista desde hace ya más de una década, la introducción de la limitación de mandatos en Cataluña permanece todavía en el terreno de los futuribles, sin que haya sido desarrollada de manera efectiva.

La tercera comunidad en sumarse a esta corriente sería Extremadura, donde a la conclusión de los veinticinco años de gobierno (1982-2007) del socialista Juan Carlos Rodríguez Ibarra el popular José Antonio Monago impulsó durante su breve presidencia la adopción de la Ley 1/2014, de 18 de febrero, de regulación del estatuto de los cargos públicos del Gobierno y la Administración de la

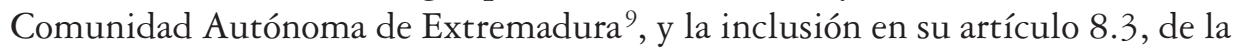

7 Consejo Consultivo de Castilla-La Mancha, «Dictamen número 44/1997, de 24 de junio», Consideración IV, in fine (en línea en http://consultivo.jccm.es/documentos/dictamenes/04497.pdf). De este modo el Presidente Bono podría en efecto ocupar otros siete años más -21 en total - el Palacio de Fuensalida.

8 BOE n. ${ }^{\circ} 172$, de 20.07.2006.

9 BOE n. ${ }^{\circ}$ 56, de 06.03 .2014 
cláusula en virtud de la cual «No podrá ser elegido presidente de la Junta de Extremadura quien ya hubiese ostentado este cargo durante dos mandatos sucesivos, salvo que hayan pasado cuatro años desde la terminación de su mandato y sin que en ningún caso pueda ser elegido quien hubiera ostentado este cargo durante al menos ocho años».

Meses después, también la Comunidad de Murcia daría un paso semejante al aprobar la Ley 7/2014, de 21 de noviembre, de modificación de la Ley 6/2004, de 28 de diciembre, del Estatuto del Presidente y del Consejo de Gobierno de la Región de Murcia ${ }^{10}$. Con una dicción distinta en su literalidad pero muy similar en sus efectos a la extremeña — la ley murciana se limitaba a afirmar que «No podrá ser elegido Presidente de la Comunidad Autónoma quien ya hubiese ostentado este cargo durante dos mandatos»— probablemente lo más reseñable de la misma fuera, de una parte, lo innecesaria que resultaba en una comunidad que había tenido seis presidentes en treinta años, y de otra su rotundidad: mientras que las disposiciones anteriormente citadas habían quedado enmarcadas, y hasta incluso disimuladas, en textos de amplio alcance y prolijo articulado, ésta se enmarcaba en una ley de artículo único, gestada a los solos efectos de introducir esta práctica en el ordenamiento autonómico murciano.

En última instancia, este repaso del estado de la cuestión en España no quedaría completo sin hacer una referencia a las dos comunidades en las que la limitación de mandatos se halla actualmente sobre la mesa.

En Andalucía, la oposición liderada por el Partido Popular registró a comienzos de 2017 una proposición de ley encaminada a la modificación de la Ley del Gobierno de la de Andalucía [...] para declarar inelegibles como Presidente de la Junta a los miembros del Parlamento andaluz «que hayan ejercido la Presidencia de la Junta durante dos legislaturas» y para que no puedan ser designados como titulares de vicepresidencias o consejerías «aquellos que hayan ostentado estos cargos durante dos legislaturas, salvo que hayan transcurrido cuatro años desde la terminación de su último mandato» ${ }^{11}$. La iniciativa del Partido Popular fue respondida desde la mayoría socialista en la cámara y la propia Junta de Andalucía llevando el asunto al Consejo Consultivo de la Comunidad, quien en su dictamen de 7 de junio de 2017 estimó que aunque el fondo de la propuesta no era incompatible con la Constitución, sí lo era su introducción en el ordenamiento jurídico andaluz mediante una simple reforma legislativa, toda vez que

10 BOE de 23.12.2014

11 G. P. Popular Andaluz, «Proposición de Ley relativa a modificación de la Ley 6/2006, de 24 de octubre, del Gobierno de la Comunidad Autónoma de Andalucía» (en línea en www. parlamentodeandalucia.es/webdinamica/portal-web-parlamento/actividadparlamentaria/ tramitacionencurso/legislativas.do? numexp=10-16/PPL-000009). 
el silencio del Estatuto sobre el particular no podía ser entendido como desentendimiento respecto de la cuestión, sino como una tácita negativa a su introducción, solo susceptible de ser revertida mediante la correspondiente reforma estatutaria. En consecuencia, la proposición del Partido Popular no era «jurídicamente viable», ya que debía estar «forzosamente contemplada en el Estatuto de Autonomía» ${ }^{12}$.

Finalmente, el 23 de marzo pasado la Asamblea regional de Madrid aprobó por unanimidad la toma en consideración de una Proposición de Ley presentada por Ciudadanos para la reforma de la Ley 1/1983, de Gobierno y Administración de la Comunidad de Madrid al objeto de limitar a dos los mandatos del Presidente de la Comunidad ${ }^{13}$. Proposición que pese a las apariencias tiene todavía un futuro incierto por delante, toda vez que el entusiasmo del partido naranja — que cifraba en la misma la clave para minimizar en la Comunidad de Madrid «problemas como la corrupción, problemas como las redes clientelares, o problemas como la endogamia política», dado que existía «constancia histórica y empírica de que los mandatos que van más allá de ocho años son caldo de cultivo perfecto para que se extiendan las tramas de corrupción»- ${ }^{14}$ no parecía ser del todo compartido por el Partido Popular - mayoritario en la cámara - que se mostraba favorable a la misma en cuanto al fondo, pero dubitativo en cuanto a la forma; mientras que la propia Presidenta de la Comunidad ya había hecho pública con anterioridad su preferencia por insertar esta medida en el marco de una reforma más amplia del Estatuto de Autonomía y por extender sus consecuencias a todos los miembros del Consejo de Gobierno de la Comunidad ${ }^{15}$.

Visto lo visto, al menos cuatro conclusiones emergen a simple vista del modo en el que las Comunidades Autónomas españolas han venido abordando hasta el día de hoy la cuestión de la limitación de mandatos. La primera es que estamos lejos de poder constatar una generalizada preocupación por el asunto, toda vez

12 Consejo Consultivo de Andalucía, «Dictamen núm. 0358/2017 de 07.06.2017: Consulta facultativa sobre la posible inconstitucionalidad de los preceptos de la Proposición de Ley 10-16/PPL-000009, relativa a la modificación de la Ley 6/2006, de 24 de octubre, del Gobierno de la Comunidad Autónoma de Andalucía» (en línea en www.juntadeandalucia.es/consejoconsultivo/dictamenes/consulta-de-dictamenes).

13 «Toma en consideración de la Proposición de Ley PROP. L-3/2017 RGEP. 1625, presentada por el Grupo Parlamentario de Ciudadanos, de modificación de la Ley 1/1983», Diario de Sesiones de la Asamblea de Madrid n. ${ }^{\circ} 414$, de 23.03.2017, p. 24.620.

14 Velasco, P., «La Asamblea aprueba por unanimidad estudiar la limitación de los mandatos para la Presidencia de la Comunidad», Madrid Diario de 23.03.2017.

15 Treceño, J., «Cristina Cifuentes aprueba modificar el Estatuto de autonomía de la Comunidad de Madrid», El Mundo, de 23.05.2016. 
que apenas seis — de diecisiete — se han molestado en debatir sobre el particular, y apenas tres - Castilla-La Mancha, Extremadura y Murcia - han llegado a legislar al respecto. La segunda es que parece haber una cierta unanimidad en que ocho años — o dos legislaturas — en el poder es la cifra mágica a partir de la cual el riesgo de hundirse en la corrupción se multiplica hasta el extremo de justificar la limitación de mandatos. La tercera es que la misma solo parece contemplarse como conveniente para los titulares del poder ejecutivo —y en particular, para su máximo responsable autonómico — sin que en ningún caso se haya acordado su aplicación a los miembros de las asambleas legislativas. Y por último, que la cuestión del rango normativo de la limitación de mandatos ha sido objeto de una valoración digamos que ambivalente, toda vez que en los casos en los que se ha instaurado lo ha sido por medio de una reforma legislativa, mientras que la necesidad de su inserción en el propio estatuto de autonomía solo ha sido planteada por quienes deseaban oponerse a las mismas.

De hecho, el del rango normativo parece estar emergiendo también como un aspecto clave del debate en el ámbito nacional, aunque tal vez no tanto como consecuencia del surgimiento de una razonable duda jurídica, como de la conveniencia para aquellos menos interesados en que éste llegue a buen fin de contar con un útil recurso dilatorio. No parece casual que mientras José Manuel Villegas —número dos de Ciudadanos, formación impulsora de la inclusión de la medida en el pacto de gobierno con el Partido Popular-, e Irene Montero portavoz parlamentaria de Podemos - ponían de manifiesto su plena coincidencia «en fondo y forma» con la estrategia de introducir la limitación de mandatos para el jefe del ejecutivo mediante una simple modificación de la Ley del Gobierno ${ }^{16}$, el coordinador general del Partido Popular, Fernando Martínez-Maíllo, hiciera patente las dudas que le suscitaba el modo de llevarlo a cabo pues, según su opinión, sería necesaria para ello una reforma constitucional que contara con el concurso de otras fuerzas políticas ${ }^{17}$. Postura, al parecer, compartida también por el Partido Socialista ${ }^{18}$.

16 Ruiz de Almirón, V., «Total sintonía entre Cs y Podemos para limitar los mandatos», $A B C$ de 11.03.2017, p. 19.

17 Europa Press, «El PP dice que mantiene dudas legales sobre limitar mandatos y que Cs lo sabía cuando firmaron su pacto de investidura» (en línea en www.europapress.es/nacional/ noticia-pp-dice-mantiene-dudas-legales-limitar-mandatos-cs-sabia-cuando-firmaron-pactoinvestidura-20170227150434.html)

${ }^{18}$ MARTínez, D., «El PSOE rechaza la propuesta de Ciudadanos de limitar mandatos sin tocar la Constitución», Voz Pópuli de 14.03.2017. 


\section{LA CAMBIANTE ACOGIDA DE LA LIMITACIÓN DE MANDATOS EN EL CONSTITUCIONALISMO COMPARADO}

El origen histórico de esta práctica coincide con el del nacimiento del constitucionalismo. Decimos práctica y no regla o norma, porque en el primer lugar en que arraigó — los Estados Unidos, cuyo primer presidente renunció en 1796 a postularse para un tercer mandato pese a que la Constitución no se lo prohibiese y la ciudadanía estuviera claramente inclinada a concedérselo- la limitación de mandatos del Presidente permaneció como una costumbre constitucional sin reflejo alguno en la letra de su Carta Magna durante casi un siglo y medio, hasta que después de los excepcionales cuatro mandatos de Franklin D. Roosevelt (1933-1945) la XXII Enmienda, aprobada en 1951, convirtiera los «term limits» en ley ${ }^{19}$. En cuanto a su origen geográfico, es notorio que la institución -íntimamente ligada al constitucionalismo liberal y a los sistemas de corte presidencialista—, arraigó de manera especial en el continente americano, alcanzando en alguna de sus repúblicas la categoría de principio fundamental de su sistema político, de manera que en fecha tan temprana como 1819 Argentina limitó la reelección de su Presidente a una sola vez, Chile limitó también a dos los mandatos presidenciales reduciendo además la duración del segundo mandato en su Constitución de 1822; y Méjico estableció la renovación anual de su Presidencia colegiada en la Constitución de 1814. En palabras de Penfold, Corrales y Hernández:

«América Latina mostró desde hace más de un siglo un sesgo constitucional en contra de la reelección con miras a abolir los personalismos políticos y el continuismo. La reelección fue vista como un mecanismo que le otorgaría al presidente excesivos poderes y que le permitiría usar las prerrogativas de su posición para debilitar a sus adversarios, socavar la división de poderes y garantizar así su continuidad. Una segunda razón fue más bien pragmática: la prohibición de la reelección consecutiva incrementaba las probabilidades de alternar el poder con potenciales adversarios y por lo tanto disminuía tanto los beneficios de ejercer la presidencia como los costos de perder las elecciones. En teoría, este tipo de esquema inducía mayores consensos políticos y facilitaba la transición democrá-

19 Para una correcta síntesis de la cuestión, véase GARCía LópEz, E., «Irreelegibilidad, inelegibilidad e incompatibilidad parlamentaria: Los artículos 23 y 70 de la Constitución y las razones políticas de la prohibición de ser reelegido», Asamblea. Revista Parlamentaria de la Asamblea de Madrid n. 14 (2006), pp. 3-21, en pp. 3-9. 
tica, pues permitía a los actores de oposición mejores condiciones políticas para aceptar voluntariamente las reglas de juego constitucionales» ${ }^{20}$.

El ámbito del Poder Ejecutivo ha sido donde mayor éxito y expansión ha conocido la limitación de mandatos, siendo su vigencia en el ámbito del Legislativo notablemente más reducida, y hasta testimonial ${ }^{21}$. Sin embargo esa expansión no solo se ha detenido, sino que incluso se ha revertido en los últimos años, en lo que constituye un fenómeno que conviene tener en cuenta cuando de extender su vigencia a nuestro país se trata.

20 Penfold, M., Corrales, J. y Hernández, G., «Los Invencibles: La reelección presidencial y los cambios constitucionales en América Latina», Revista de Ciencia Política n. ${ }^{\circ} 3$ (2014), pp. 537-559.

${ }^{21}$ Pues a decir de IbáÑez-Macías, A., «La limitación de mandatos parlamentarios: una técnica constitucional para la renovación permanente de las élites políticas», Revista de Derecho UNED, n. ${ }^{\circ} 17$ (2015), pp. 341-389, en p. 345) solo la encontramos en Costa Rica, Filipinas, Méjico y EE. UU. En Costa Rica los miembros de la Asamblea Legislativa son elegidos para un mandato de cuatro años, exigiendo el artículo 107 de la Constitución que transcurra una legislatura antes de que puedan concurrir a nuevos comicios (Vid. Constitución Política de la República de Costa Rica de 7 de noviembre de 1949; en línea en http://pdba.georgetown.edu/Parties/CostaRica/Leyes/ constitucion.pdf); en Filipinas el artículo VI, sección 4, de la Constitución (The Constitution of the Republic of the Philippines de 2 de febrero de 1987, en línea en www.gov.ph/ constitutions/1987-constitution/) fija el mandato de los senadores en seis años y el de los representantes en tres, con un límite máximo de dos legislaturas en el Senado y tres en la Cámara Baja; una cláusula que dista mucho de haber logrado el objetivo para el que debió ser creada en un país que, si por algo se caracteriza, es por el monopolio político de las dinastías que vienen dominando su vida política y económica desde hace décadas; en Méjico, la Constitución de 1917 (Constitución Política de los Estados Unidos Mexicanos de 5 de febrero de 1917, en línea en www.diputados. gob.mx/LeyesBiblio/pdf/1_240217.pdf) prohibe la reelección consecutiva de los legisladores desde 1933, afirmando en su artículo 59 que: «Los Senadores podrán ser electos hasta por dos periodos consecutivos y los Diputados al Congreso de la Unión hasta por cuatro periodos consecutivos.» En el caso de los Estados Unidos no existe una previsión de limitación de mandatos del legislativo en la Constitución federal, y solo a partir de 1990 se han promovido en diferentes Estados iniciativas legislativas populares para introducir la limitación de mandatos en las constituciones estatales o, en su caso, en sus respectivas legislaciones. Hasta nuestros días, y según los datos de la National Conference of State Legislatures (vid. «State Constitutional and Statuory provisions for term limits», en línea en www.ncsl.org/research/about-state-legislatures/term-limitsprovisions-state-law-and-constitutions.aspx) quince estados han llegado a introducir la restricción a sus legisladores estatales: en concreto California, Colorado, Oklahoma, Arkansas, Michigan, Florida, Ohio, Dakota del Sur, Montana, Arizona, Misuri, Maine, Luisiana, Nevada y Nebraska. No obstante, la regulación dista mucho de ser uniforme puesto que en algunos estados la limitación es absoluta, mientras que en otros se trata tan solo de un veto a la reelección consecutiva; los plazos máximos de permanencia en el escaño oscilan entre los seis y los doce años, y existe también disparidad en cuanto a la posibilidad o no de cambiar de cámara una vez agotado el plazo máximo en una de ellas. 
En efecto, si hasta mediados de la década de los noventa eran mayoría las constituciones en América Latina que vetaban o limitaban la reelección presidencial, en los últimos veinte años varias de éstas repúblicas han afrontado reformas constitucionales en sentido diametralmente opuesto ${ }^{22}$. Las primeras reformas optaron por el modelo de reelección consecutiva, limitada en el número de mandatos ${ }^{23} \mathrm{y}$ se llevaron a término en Perú (1993) ${ }^{24}$, Argentina (1994) ${ }^{25}$ y Brasil (1997) ${ }^{26}$ en todos los casos impulsadas por gobiernos neoliberales como los de Alberto Fujimori, Carlos Menem y Fernando H. Cardoso — coincidencia ideológica ésta que evidencia la inexactitud de atribuir de forma generalizada un sesgo político progresista a las iniciativas favorecedoras de la reelección en las repúblicas latinoamericanas- Con todo, los cambios más radicales de estas dos últimas décadas corresponden a Venezuela, Ecuador, Nicaragua y Honduras que han introducido la posibilidad de reelección indefinida de sus presidentes, y el más controvertido a Bolivia, en donde la cuestión dista de haber quedado definitivamente zanjada; de modo que son solo cuatro los países de la región —-Guatemala ${ }^{27}$, Paraguay ${ }^{28}$,

22 Serrafero, M., «La reelección presidencial indefinida en América Latina», Revista de Instituciones, Ideas y Mercados, n. ${ }^{\circ} 54$ (2011), pp. 225-259.

${ }^{23}$ Carey, J., "The reelection debate in Latin America», Latin American Politics and Society n. ${ }^{\circ} 45$ (2003), pp. 119-133.

${ }^{24}$ Constitución Política del Perú, artículo 112: «El mandato presidencial es de cinco años. El Presidente puede ser reelegido de inmediato para un período adicional. Transcurrido otro período constitucional, como mínimo, el ex presidente puede volver a postular, sujeto a las mismas condiciones». En 2000 este artículo fue reformado y se introdujo la reelección solo en mandatos alternos (en línea en www4.congreso.gob.pe/ntley/Imagenes/Constitu/ Cons1993.pdf).

${ }_{25}$ Constitución de la Nación Argentina, artículo 90: «El Presidente y vicepresidente duran en sus funciones el término de cuatro años y podrán ser reelegidos o sucederse recíprocamente por un solo período consecutivo. Si han sido reelectos o se han sucedido recíprocamente no pueden ser elegidos para ninguno de ambos cargos, sino con el intervalo de un período» (En línea en http:// servicios.infoleg.gob.ar/infolegInternet/anexos/0-4999/804/norma.htm).

${ }^{26}$ Constitución de la República Federativa del Brasil, artículo 82: «El mandato del Presidente de la República es de cuatro años, y tendrá inicio el 1 de enero del año siguiente al de su elección» (En línea en www.senado.gov.br/atividade/const/con1988/con1988_12.07.2016/ art_82_.asp).

${ }^{27}$ Constitución Política de la República de Guatemala, artículo 184: «Elección del Presidente y Vicepresidente de la República. El Presidente y Vicepresidente de la República, serán electos por el pueblo para un período improrrogable de cuatro años, mediante sufragio universal y secreto» (en línea en www.oas.org/juridico/mla/sp/gtm/sp_gtm-int-text-const.pdf)

${ }_{28}$ Constitución de la República del Paraguay, artículo 229: «El Presidente de la República y el Vicepresidente durarán cinco años improrrogables en el ejercicio de sus funciones, a contar desde el quince de agosto siguiente a las elecciones. No podrán ser reelectos en ningún caso» (en línea en www.oas.org/juridico/mla/sp/gtm/sp_gtm-int-text-const.pdf). 
Méjico ${ }^{29}$ y Colombia - ${ }^{30}$ que mantienen la tradicional prohibición absoluta de reelección presidencial ${ }^{31}$.

Centrándonos en los casos que acabamos de subrayar ${ }^{32}$ la Constitución chavista de 1999 estableció en Venezuela la posibilidad de que el Presidente de la República desempeñase su cargo durante dos mandatos consecutivos. A punto de cumplirse sus primeros diez años en el poder, el Presidente Chávez promovió en 2007 un referéndum de reforma constitucional para introducir la reelección presidencial indefinida, pero esta eventualidad fue rechazada por un estrecho margen de votos. En un segundo envite, una nueva consulta para la modificación de varios artículos constitucionales celebrada en 2009, habilitó la reelección de todos los cargos de elección popular de forma indefinida, lo que obviamente incluía la Presidencia ${ }^{33}$. De hecho, Chávez logró ser elegido para un tercer y hasta para un cuarto mandato, en 2012, que no llegó a ejercer de forma efectiva,

29 Constitución Política de los Estados Unidos Mexicanos, artículo 83: «El Presidente entrará a ejercer su encargo el $1 .^{\circ}$ de diciembre y durará en él seis años. El ciudadano que haya desempeñado el cargo de Presidente de la República, electo popularmente, o con el carácter de interino, provisional o substituto, en ningún caso y por ningún motivo podrá volver a desempeñar ese puesto» (en línea en www.diputados.gob.mx/LeyesBiblio/pdf/1_240217.pdf).

30 En puridad, Colombia no mantiene este principio, sino que lo ha introducido en su ordenamiento constitucional (por Ley núm. 2, de 1 de julio de 2015) cuando hasta ese momento venía permitiendo la reelección limitada a dos mandatos, probablemente como reacción a la reelección de los dos últimos presidentes (Álvaro Uribe y Juan Manuel Santos) de la nación. Vid. Constitución Política de Colombia, artículo 197: «No podrá ser elegido Presidente de la República el ciudadano que por cualquier título hubiere ejercido la presidencia. [...] La prohibición de la reelección solo podrá ser reformada o derogada mediante referendo de iniciativa popular o asamblea constituyente» (en línea en www.corteconstitucional.gov.co/inicio/Constitucion\%20politica\%20 de\%20Colombia\%20-\%202015.pdf).

31 Por completar el panorama, el Presidente de la República puede optar a la reelección, siempre y cuando se trate de mandatos alternos en Uruguay, El Salvador, Chile, Panamá, Costa Rica, Perú y Haití; y puede optar a la reelección presidencial consecutiva, con un límite en el número máximo de mandatos en Estados Unidos, Ecuador, Bolivia, y República Dominicana.

32 Vid. Aquino, J. R., «Reelección presidencial y equidad en las campañas electorales», Cuadernos de CAPEL n. 57 (2012), pp. 247-278. Para un panorama si cabe más completo, consúltese TREminio SÁNCHEZ, I., Llegaron para quedarse... los procesos de reforma a la reelección presidencial en América Latina 1999-2011, Tesis doctoral dirigida por Mercedes García Montero, Universidad de Salamanca, 2013 (en línea en https://gredos.usal.es/jspui/handle/10366/123059).

33 Constitución de la República Bolivariana de Venezuela, artículo 230: «El período presidencial es de seis años. El Presidente o Presidenta de la República puede ser reelegido o reelegida.» (En línea en www.minci.gob.ve/wp-content/uploads/2011/04/CONSTITUCION.pdf). 
pues hallándose ya gravemente enfermo delegó sus funciones interinamente en su Vicepresidente Nicolás Maduro, para fallecer en marzo del año siguiente ${ }^{34}$.

Por lo que respecta a Ecuador, la Constitución impulsada por el Presidente Rafael Correa, popularmente refrendada en septiembre de 2008, supuso el abandono de la alternancia obligatoria entre mandatos presidenciales e introdujo la posibilidad de que el Presidente concurriera a una sola reelección inmediata $^{35}$. Correa revalidó su mandato merced a unas nuevas elecciones en 2009 y otro tanto volvió a suceder en 2013, toda vez que se asumió que la limitación de mandatos contenida en la Constitución solo podía ser de aplicación a partir de la fecha de su entrada en vigor, de modo que el de 2009 computaría como el primero, y el de 2013 como el segundo mandato de Correa, que permaneció en su puesto hasta el pasado mes de mayo de 2017 convirtiéndose en el Presidente que más tiempo ha ostentado tal responsabilidad en toda la historia ecuatoriana. El último capítulo de este proceso se verificó en junio de 2014 , cuando el legislativo ecuatoriano acordó suprimir en el texto del artículo 144 la expresión "por una sola vez», dando luz verde de este modo a la reelección presidencial irrestricta ${ }^{36}$.

Por lo que hace a Nicaragua, el retorno de los ex guerrilleros del Frente Sandinista de Liberación Nacional (FSLN) al poder en 2006 convirtió a su líder histórico Daniel Ortega, nuevamente, en Presidente de la República. A tenor

34 Sarmiento Erazo, J. P., «Populismo constitucional y reelecciones, vicisitudes institucionales en la experiencia sudamericana», Estudios constitucionales: Revista del Centro de Estudios Constitucionales (de Chile) n. ${ }^{\circ} 11 / 1$ (2013), pp. 569-602.

35 Constitución del Ecuador, artículo 144: «El período de gobierno de la Presidenta o Presidente de la República se iniciará dentro de los diez días posteriores a la instalación de la Asamblea Nacional, ante la cual prestará juramento. En caso de que la Asamblea Nacional se encuentre instalada, el período de gobierno se iniciará dentro de los cuarenta y cinco días posteriores a la proclamación de los resultados electorales. La Presidenta o Presidente de la República permanecerá cuatro años en sus funciones y podrá ser reelecto por una sola vez (en línea en www.asambleanacional.gov.ec/documentos/constitucion_de_bolsillo.pdf).

36 La norma no afectó de manera inmediata a Correa ya que en ella se previó una vacatio legis extendida hasta el 24 de mayo de 2017, por lo que el entonces Presidente quedó al margen de la posibilidad de un nuevo mandato, aunque ciertamente podría concurrir a futuras elecciones. La norma fue llevada ante el Tribunal Constitucional para obtener de él un pronunciamiento contrario a la técnica legislativa elegida, de forma que las enmiendas requiriesen la aprobación en referéndum y no su mera tramitación en la Cámara. Finalmente, la Corte Constitucional validó en octubre de 2014 el procedimiento de reforma elegido y en diciembre de 2015, la Asamblea Legislativa ecuatoriana aprobó la introducción de las enmiendas, con el efecto antedicho. Véase al respecto Treminio SÁnCHeZ, I., «La reforma constitucional de Rafael Correa: el caso de la reelección presidencial en Ecuador», América latina boy: Revista de ciencias sociales n. 67 (2014), pp. 65-90. 
del artículo 147 de la Constitución de 1987 según el cual «No podrá ser candidato a Presidente ni Vicepresidente de la República: a) El que ejerciere o hubiere ejercido en propiedad la Presidencia de la República en cualquier tiempo del período en que se efectúa la elección para el período siguiente, ni el que la hubiere ejercido por dos períodos presidenciales» ${ }^{37}$, Ortega, que ya había ostentado la condición de Presidente en el periodo 1985-1990 —amén de haberlo sido de facto entre 1979-1985-, se hallaba claramente inhabilitado para optar a un nuevo mandato a la conclusión del que había comenzado a disfrutar el 10 de enero de 2007. La redacción del texto constitucional — gestado, por cierto, bajo mayoría sandinista - ofrecía pocas dudas de que nos halláramos ante un ejemplo de limitación de mandatos de doble alcance, por el que se vetaba tanto la reelección inmediata o consecutiva, como el que una misma persona llegase a la Presidencia por tercera vez, en cualesquiera circunstancias.

Sin embargo, antes de la conclusión de su mandato Ortega anunció su voluntad de optar a una nueva reelección. Para ello el Frente Sandinista intentó en primer lugar acometer una reforma constitucional, pero desistió de su propósito al comprobar la imposibilidad de reunir los votos necesarios en la cámara. Así pues, decidió vindicar su causa ante la Sala Constitucional de la Corte Suprema, con razonables expectativas de éxito puesto que, como explica Martínez-Barahona, en el año 2000 su antecesor Arnoldo Alemán y él mismo habían pactado una serie de medidas que configuraban «de facto, un reparto de las principales instituciones del país», en el que al FSLN le había correspondido una amplia capacidad de influencia sobre este órgano. En consecuencia, la resolución de la Sala fue propicia a los intereses de Ortega en base a una pueril invocación de la obligación del Estado de «eliminar los obstáculos que impidan de hecho la igualdad entre los nicaragüenses y su participación efectiva en la vida política, económica y social del país» contenida en artículo 48 de la Constitución, de la que dedujo la inaplicabilidad del artículo 147 al ciudadano Daniel Ortega por generarle un agravio frente a los demás ciudadanos que concurrían a las elecciones ${ }^{38}$. Superada su causa de inelegibilidad, Daniel Ortega ganó las elecciones presidenciales de 2011 por amplísima mayoría, y con el terreno ya abonado para ello acometió en 2014 la reforma de diversos artículos

37 Constitución Política de la República de Nicaragua (en línea en www.oas.org/juridico/ spanish/mesicic3_nic_const.pdf; fecha de consulta: 15 de junio de 2017).

38 Vid. Martínez-Barahona, E., y Brenes Barahona, A., «Y volver, volver, volver...». Un análisis de los casos de intervención de las cortes supremas en la reelección presidencial en Centroamérica», Anuario de Estudios Centroamericanos n. 38 (2012), pp. 109-136 y «Cortes Supremas y candidaturas presidenciales en Centroamérica», Revista de Estudios Políticos n. ${ }^{\circ} 158$ (2012), pp. $165-206$ 
de la Constitución, entre los que se encontraba el repetidamente citado 147 , del que desapareció toda mención a las causas de inelegibilidad ${ }^{39}$. Así, quedó abierta definitivamente en Nicaragua la vía para la reelección indefinida del Presidente de la República, aprovechada por el propio Ortega en 2016 cuando — con su esposa Rosario Murillo como candidata a la Vicepresidencia- logró su cuarta victoria electoral ${ }^{40}$.

Por último, si un caso resulta llamativo por su complejidad y por la polarización social generada en torno suyo es el boliviano. Tras su victoria en las elecciones de diciembre de 2005, en julio de 2006 el Presidente Evo Morales convocó unas nuevas elecciones para formar una Asamblea Constituyente, que tras un largo y complejo proceso fue capaz de gestar la nueva Constitución del Estado Plurinacional de Bolivia y lograr su aprobación en referéndum en enero de 2009. En ella el mandato presidencial pasó de cuatro a cinco años y se habilitó la posibilidad de reelección consecutiva por un solo mandato adicional ${ }^{41}$. Ello permitió a Morales ser reelegido en 2010 para el que en principio tendría que haber sido su segundo y último mandato. No obstante, y como había sucedido en Ecuador, el Tribunal Constitucional apreció que el primer periodo había de quedar fuera de este cómputo, dado que Bolivia había quedado «refundada» en 2009 de modo que el de 2010-2015 debería ser computado como su primer mandato, y el de 2015-2020 como el segundo - y ya último ${ }^{42}$.

Sin embargo en febrero de 2016 el Presidente Morales impulsó un nuevo referéndum para reformar la Constitución y permitir su concurrencia a una nueva reelección. El Presidente justificó la necesidad de un nuevo mandato por la conveniencia de concluir la ardua tarea legislativa de transformación profunda de Bolivia. Contrariamente a lo que avanzaban los sondeos de intención de voto, la reforma fue rechazada y, por tanto, el actual será el último mandato del carismático Morales. Aunque cabe recordar que el artículo 168 le permite presentarse nuevamente, una vez transcurra el mandato de quien le suceda y — por otra parte- que los intentos tanto de desacreditar la limpieza del referéndum

39 Ley 84 de Reforma Parcial a la Constitución Política de la República de Nicaragua (en línea en: http://legislacion.asamblea.gob.ni/normaweb.nsf/b92aaea87dac762406257265005d21f7/ a0c959ffe15fdf4906257c7e0059f947? OpenDocument).

40 Vargas Lima, A. E. «La reelección presidencial en la jurisprudencia del Tribunal Constitucional Plurinacional de Bolivia», Revista Boliviana de Derecho n. ${ }^{\circ} 19$ (2015), pp. 446-469.

41 Nueva Constitución Política del Estado, artículo 168: «El periodo de mandato de la Presidenta o del Presidente y de la Vicepresidenta o del Vicepresidente del Estado es de cinco años, y pueden ser reelectas o reelectos de manera continua por una sola vez» (en línea en www.justicia. gob.bo/index.php/normas/doc_download/35-nueva-constitucion-politica-del-estado).

42 Martínez Ahrens, J., «El gran día de Ortega I de Nicaragua», El País de 07.112016. 
de 2016, como de acometer una nueva reforma constitucional están lejos de haber sido descartados.

De los casos enunciados — que, como hemos advertido, no son todos cuantos podríamos haber traído a colación-, parece deducirse que la institución de la limitación de mandatos se encuentra en manifiesto retroceso, precisamente en la región del planeta donde nació: en las Américas. Y ello en medio de apelaciones al empoderamiento de las clases trabajadoras, la lucha contra las elites y la profundización en la democracia — por más que lo que en realidad observemos sea un innegable deslizamiento hacia el populismo y hasta el caudillismo, el menosprecio hacia partidos y parlamentos, el aherrojamiento de la prensa libre y la libre empresa- que resultan ser objetivos no muy distintos de los perseguidos en España por quienes proponen precisamente lo contrario: la instauración de limitaciones a los mandatos. Todo ello arroja una sombra de duda respecto de las supuestas bondades esta institución, obligando a ponderar con exactitud qué peligros intenta conjurar y qué capacidad tiene para ello, y a medir con exactitud qué distancia media entre aquellos sistemas político-sociales y el nuestro.

\section{3. ¿SERÍA ÚTIL INTRODUCIR LA LIMITACIÓN DE MANDATOS EN ESPAÑA?}

Los actores políticos que han defendido la limitación de mandatos de los cargos electos en España lo han venido justificando en base a los efectos benéficos que dicha medida habría de deparar, en particular en la lucha contra la corrupción y en la tarea de procurar la deseable renovación de nuestras elites políticas. Esa sería, sin ir más lejos, la postura adoptada por el portavoz de Ciudadanos en la Asamblea de Madrid, Ignacio Aguado, para quien la medida propuesta por su partido en esa Comunidad «puede ayudar a reducir la corrupción y las redes clientelares», toda vez que «tenemos constancia histórica y empírica de que los mandatos que van más allá de ocho años son caldo de cultivo perfecto para que se extiendan las tramas de corrupción» ${ }^{43}$.

El planteamiento resulta desde luego atrayente, pero antes de darlo por bueno sería conveniente someterlo a un análisis pormenorizado que cuando menos ayudase a revelar (a) si en efecto existe una constancia empírica de que los mandatos de duración superior a los ocho años generan más casos de corrupción -o casos más graves, o mayores dificultades a la hora de castigarlos- que los de mayor brevedad; (b) si en efecto sería deseable — en términos de calidad demo-

43 SÁnChez, E., «La Asamblea de Madrid da el primer paso para limitar los mandatos a ocho años», El País de 24.03.2017. 
crática - que nuestras elites política se renovasen con mayor frecuencia de lo que lo hacen y (c) si el instituto de la limitación de mandatos sería susceptible de generar — en los términos en los que habitualmente es planteado- los efectos taumatúrgicos que le asignan sus defensores.

\subsection{La perpetuación en el poder como causa propiciatoria de la corrupción}

Carece de sentido abordar el estudio de las cuestiones relacionadas con la limitación de mandatos sin contar previamente con un soporte fáctico que nos permita alejarnos de la mera especulación. A menos que queramos mantener el debate en el más estricto, y estéril, plano de la filosofía política — lo que no es el caso- habremos de comenzar poniendo sobre la mesa datos estadísticos que nos permitirán dilucidar si la concatenación de mandatos en el ejecutivo, o la reiterada reelección en el legislativo, son norma o anécdota entre nosotros, y si de ello cabe derivar alguna consecuencia en lo tocante al fenómeno de la corrupción. Ello nos ofrecerá un primer indicio acerca de si la introducción en nuestro ordenamiento jurídico de algún tipo de limitaciones a la reelegibilidad de los cargos de elección popular ha de considerarse necesidad, precaución o simple capricho.

Por lo que toca a la longevidad de mandatos de los presidentes del Gobierno desde el comienzo de la Transición, y de los presidentes de las Comunidades Autónomas a partir de su constitución como tales a comienzos de los ochenta, habremos de concluir que no se prodigan los de duración superior a ocho años.

De los seis Presidentes del Gobierno que ha tenido nuestro país, solo Felipe González (1982-1996) permaneció en el poder durante más de dos legislaturas. Adolfo Suárez (1976-1981) no agotó su segundo mandato; Leopoldo CalvoSotelo (1981-1982) ocupó el cargo menos de media legislatura; y tanto José María Aznar (1996-2004) como José Luis Rodríguez Zapatero (2004-2011) se conformaron con dos, cediendo el testigo a sus sucesores sin ni siquiera intentar optar a un tercer mandato. Aunque en el caso del actual Presidente (Mariano Rajoy: 2011-) sea todavía una incógnita tanto si llegará a agotar su segundo mandato, como si optará a un tercero — recuérdese que entre diciembre de 2015 y octubre de 2016 presidió un Gobierno en funciones-, lo cierto es que el balance de estos cuarenta y un años de democracia parece indicar que nuestro sistema político no es especialmente propicio para los mandatos prolongados, obedeciendo el caso único de Felipe González a la conjunción de una circunstancia histórica y unas características personales en ambos casos singulares. 
En cuanto a los Presidentes de las Comunidades Autónomas, cuyo número asciende a 111 desde la puesta en marcha del sistema autonómico hasta hoy, el hecho es que únicamente 15 (el 13'5\% del total) han llegado a desempeñar sus responsabilidades al frente del ejecutivo autonómico durante más de ocho años consecutivos, y de ellos solo diez lo han hecho durante mas de doce años: Joan Lerma (PSOE), que fue President de la Generalitat Valenciana durante 13 años; José Antonio Ardanza (PNV), lehendakari del País Vasco durante 14 años; Miguel Sanz (UPN), Presidente de la Diputación Foral de Navarra durante 15 años; Manuel Fraga Iribarne (PP), 15 años en Galicia; Juan Vicente Herrera (PP), 16 años en Castilla y León; Manuel Chaves González (PSOE), 19 años en Andalucía; Pedro Sanz (PP), 20 años en La Rioja; José Bono (PSOE), 21 años en Castilla-La Mancha; Jordi Pujol (CiU), President de la Generalitat de Catalunya durante 23 años, y Juan Carlos Rodríguez Ibarra (PSOE), cuyo mandato en Extremadura se prolongó 25 años.

Así las cosas, no parece justificado hablar de un fenómeno que se repita con insistencia preocupante. Y menos todavía que sea posible sostener la existencia de una relación causal directa entre los mandatos prolongados y la corrupción de los mandatarios. En cuanto a los Presidentes del Gobierno, la ecuación es sencilla desde el momento en que ninguno de ellos ha resultado jamás enjuiciado - y menos aun condenado - por caso alguno de corrupción. Y por lo que respecta a los presidentes autonómicos, si bien es cierto que dos de los más veteranos se han visto recientemente implicados en graves escándalos de corrupción ${ }^{44}$, no lo es menos que los ocho restantes, repetidamente reelegidos, presentan hojas de servicios sin tacha, mientras que a sensu contrario, no han faltado ejemplos de presidentes que pese a la brevedad de su mandato se han visto implicados en serios casos de corrupción ${ }^{45}$.

${ }^{44}$ Que todavía permanecen sub iudice en el momento de redactar estas líneas y, en consecuencia, deben ser tomados con cautela a los efectos de servir de argumento en un sentido o en otro. Hacemos referencia, primeramente, al catalán Jordi Pujol, investigado junto con su esposa e hijos por un delito continuado de blanqueo de capitales, supuestamente procedentes de las comisiones percibidas a cambio del trato de favor en adjudicaciones de obras y servicios; y al andaluz Manuel Chaves, en situación de procesado por prevaricación en el caso ERE.

45 Tales serían — salvo error u omisión, y dejando al margen el caso de Artur Mas, condenado a dos años de inhabilitación especial para empleo o cargo público y multa, pero no por corrupción sino por un delito de desobediencia-, los casos de Gabriel Urralburu, de Jaume Matas, de José Antonio Griñán y de Ignacio González: mientras que el navarro no llegó a completar su segundo mandato y acabó condenado a cuatro años de prisión por un delito de cohecho en el llamado «caso Roldán», el balear fue Presidente durante una sola legislatura, lo cual no le supuso obstáculo para acumular (hasta mayo de 2017) procedimientos penales por una muy infrecuente variedad de delitos, que incluyen la prevaricación, el cohecho, la malversación de caudales, la 
Por lo que toca al mandato de los diputados del Congreso, la documentación histórica que facilita la propia cámara ${ }^{46}$ permite comprobar que, desde la legislatura constituyente de 1977 hasta la actualidad, han sido 2.472 los diputados que han ocupado alguno de los escaños del Congreso. De ellos, rebasaron las dos legislaturas un total de 610 — apenas un 24,6\%: algo menos de una cuarta parte- - cifra que acredita que no se trata de un fenómeno excepcional, pero que en modo alguno constituye un problema endémico. Más allá de ello, encontramos 114 diputados que lo han sido durante cinco legislaturas; 57 que lo han sido en seis ocasiones; 29 en siete; y 22 en ocho; ostentando las cifras más abultadas de legislaturas en la cámara baja los ex ministros Jesús Caldera y Jorge Fernández Díaz y Jaime Javier Barrero con nueve legislaturas; el actual Presidente del Gobierno Mariano Rajoy, la ex ministra de Sanidad y ex vicepresidenta del Congreso Celia Villalobos y el histórico dirigente socialista José María Txiki Benegas con diez; y quien fuera Vicepresidente del Gobierno y vicesecretario general del PSOE, Alfonso Guerra, que ostenta la marca absoluta de permanencia con once legislaturas consecutivas.

Pues bien: el hecho es que en esta extensa relación de diputados reiteradamente reelegidos pueden contarse con los dedos de una sola mano aquellos que han llegado a romper con la tónica irreprochable de la inmensa mayoría de sus colegas de escaño ${ }^{47}$, por más que algunos de esos casos — no necesariamente los más graves- hayan alcanzado una repercusión mediática y un eco político reseñable.

apropiación indebida, la falsedad documental, el tráfico de influencias, el blanqueo de capitales, el delito fiscal y hasta el delito electoral, y que de momento se han materializado en condenas que suman ya nueve años y ocho meses de prisión y siete años más de inhabilitación especial para empleo o cargo público en los casos Palma Arena I y Nóos, resueltos respectivamente por las Sentencias de la Audiencia Provincial de Mallorca n. ${ }^{\circ}$ 18/2012, de 19.03.2012 y n. ${ }^{\circ}$ 13/2017, de 17.02.2017. Por su parte el andaluz, también presidente durante una sola legislatura, se halla procesado por el mismo asunto que su antecesor (Auto de procesamiento, dictado el 31 de mayo de 2016 en las Diligencias Previas 6645/15, del Juzgado de Instrucción n. ${ }^{\circ} 6$ de Sevilla, en línea en http://www.ecestaticos.com/file/790423c19229fca68c44167b46348b71/1464786161.pdf) solo que en su caso la acusación es de prevaricación y malversación continuada, paradójicamente delitos más graves que los acometidos por quien ocupó su mismo cargo durante un lapso de tiempo cinco veces mayor; y el madrileño, presidente durante menos de tres años (2012-2015), se halla actualmente en prisión provisional en el marco de la llamada «Operación Lezo», atribuyéndosele delitos de organización criminal, prevaricación, malversación, cohecho, blanqueo, fraude y falsificación documental.

46 Congreso de los Diputados (en línea en www.congreso.es/portal/page/portal/Congreso/ Congreso/Diputados/DiputadosTodasLegislaturas).

47 Sería el caso - de nuevo salvo error u omisión y dejando al margen el caso de Manuel Chaves, diputado en seis legislaturas pero imputado por hechos acaecidos relacionados con su etapa de gestión como Presidente de la Junta de Andalucía— de Álvaro Lapuerta, imputado en el 
Así pues, más allá de conjeturas y sobrentendidos, los datos manejados nos obligan a concluir si bien la corrupción política existe, sin duda, en España 48 ésta permanece sustancialmente alejada del palacio de la Carrera de San Jerónimo y - por lo que ahora nos importa- sin que pueda establecerse una relación de causa-efecto entre las repetidas reelecciones de los parlamentarios y el surgimiento de tramas corruptas en su entorno.

\subsection{Las supuestas bondades de la renovación de las elites políticas}

En las primeras páginas de este trabajo recordábamos el movimiento ciudadano del 15-M como origen remoto de las propuestas de limitación de mandatos, o al menos de su popularización y su incorporación al debate político español, también cabría referir a ese momento la popularización del vocablo «casta», en alusión despectiva a la clase política en general, y a los políticos profesionales instalados en los cargos de elección popular de por vida, en particular. Sin duda, la «casta» fue un felicísimo hallazgo publicitario que decodificaba el término

«Caso Gürtel» por un delito de apropiación indebida, aunque exonerado por la Audiencia Nacional en septiembre de 2016 al comprobarse su estado de demencia sobrevenida (PÉrEZ, F. J., «La Audiencia archiva la causa contra Álvaro Lapuerta por demencia sobrevenida», El País de 13.09.2016.); Virgilio Zapatero, condenado en febrero de 2017 a ocho meses de prisión por un delito de apropiación indebida en el caso de las Tarjetas Black (Sentencia 4/2017 de Sala de lo Penal de la Audiencia Nacional, de 23.02.2017; en línea en http:/estaticos.expansion.com/opinion/ documentos Web/ 2017/02/23/sentenciatarjetasblack.pdf); Rodrigo Rato, condenado a cuatro años de prisión en el mismo procedimiento por un delito continuado de apropiación indebida. e investigado por los delitos de fraude, alzamiento de bienes y blanqueo de capitales; Vicente MartínezPujalte, investigado por presuntos delitos de falsedad documental y cohecho (EFE, «El juez cita como investigado a Martínez-Pujalte y envía informes a la Audiencia Nacional», El Mundo, de 07.11.2016); y Ana Mato imputada como partícipe a título lucrativo de los delitos de malversación de caudales públicos, cohecho y prevaricación, presuntamente cometidos por su marido Jesús Sepúlveda (CAlleja, T., «El juez Ruz considera a la ministra Ana Mato partícipe a título lucrativo en el 'caso Gürtel'», Infolibre, de 24.11.2014).

48 Para un panorama más completo de la cuestión, pueden consultarse de una parte los índices elaborados por Transparency International, la organización no gubernamental con sede en Berlín dedicada a promover medidas contra la corrupción política en el ámbito internacional y promotora de su conocido índice de percepción de la corrupción (TRANSPARENCY INTERNATIONAL, Índice de percepción de la corrupción 2016, en línea en www.transparency.org/news/feature/ corruption_perceptions_index_2016\#table), y de otra el repositorio de datos sobre procesos por corrupción confeccionado por el Consejo General del Poder Judicial, con información exhaustiva actualizada trimestralmente sobre los delitos urbanísticos, de prevaricación, violación de secretos, cohecho, tráfico de influencias y malversación (PODER JUdICIAL, «Repositorio de datos sobre procesos por corrupción», en línea en www.poderjudicial.es/cgpj/es/Temas/Transparencia/Repositorio-de-datos-sobre-procesos-por-corrupcion/). 
técnico de «elites políticas» y facilitaba su recepción popular y conversión de la renovación periódica de las élites políticas en un objetivo político a conseguir, y en la limitación de mandatos en el instrumento idóneo para ello.

La idea que subyace en el planteamiento de la renovación de élites como objetivo político es la de que la alternancia en el poder forma parte de la esencia de la democracia, y que cuanto mayor y más frecuente sea la rotación entre los detentadores del poder, y mayor el número de ciudadanos que pasen de «gobernados» a «gobernantes» y viceversa, mayor será el nivel de participación política, mayor la transparencia de las instituciones, y en consecuencia mayor la calidad de la democracia. Una tesis que si a simple vista resulta muy atractiva, tal vez no lo sea tanto una vez sometida a un análisis más sosegado.

De entrada, la idea parte de una apreciación solo parcialmente correcta, cual es la de identificar a las elites políticas con los efectivos titulares de los órganos constitucionales, cuando aquel resulta ser un concepto mucho mas complejo, amplio y evanescente que no es susceptible de identificarse sin mas con éste. La experiencia demuestra que un país puede relevar periódicamente a sus primeros ministros —-Italia tuvo 18, 16 de ellos democristianos, entre 1946 y 1992 - sin que por ello el centro del poder se desplace lo más mínimo ni las elites dirigentes se renueven, de manera que la limitación de mandatos bien podría generar una mera apariencia de renovación, carente de realidad efectiva.

Adicionalmente, cabe recordar que todo oficio requiere su técnica y toda técnica precisa bien de una preparación previa, bien de un determinado tiempo de aprendizaje; y el ejercicio de las tareas de gobierno y representación no constituye una excepción. Las tareas de los parlamentarios — no digamos de los titulares del poder ejecutivo - abarcan un abanico de funciones muy amplio, por más que muchas de esas tareas resulten en buena medida desconocidas para una opinión pública muy mayoritariamente persuadida de que la actividad del parlamentario empieza y termina en la tediosa asistencia a las sesiones plenarias del Congreso. De los parlamentarios se espera que sean capaces de participar en la redacción de proposiciones de ley y en la enmienda de las de otras formaciones, de seguir de cerca la acción de gobierno y someterla a un estrecho control, de fiscalizar el diseño y la ejecución de los presupuestos, de valorar adecuadamente a quienes vayan a ser designados para desempeñar puestos en otros órganos constitucionales y un largo etcétera. Y todo ello, proyectando su acción sobre una variedad de campos prácticamente ilimitada.

Dado que nuestro sistema no contempla — entre otras cosas porque sería de todo punto contrario a la lógica democrática - la exigencia de ningún tipo de cualificación académica o de experiencia profesional para el acceso a las funciones representativas o de gobierno, no cabe más que colegir que la única diferencia 
entre un parlamentario veterano y uno que fuera a acceder por primera vez a esta función radicaría en la posesión o no de la experiencia que brinda el ejercicio del cargo a quien lo ha ostentado, y de la cual carece quien no lo ha hecho. Visto así, la idea de prescindir de quien con el transcurso del tiempo ha tenido la oportunidad de adquirir esas habilidades solo para dar paso a quienes sencillamente carecen de ellas no parece una idea muy brillante. En efecto, ante la imposibilidad política y la inviabilidad jurídica de exigir a los miembros de las cámaras que posean una formación académica o cuenten con una experiencia previa relacionada con las funciones que van a desempeñar — y más todavía, ante la implausibilidad de que incluso en los casos en que sí exista dicha formación, los parlamentarios recién elegidos estén familiarizados con el reglamento de su cámara correspondiente, ni con la dinámica parlamentaria cotidiana- la experiencia en el ejercicio de la función representativa deviene un arma insustituible para salvar el notable desajuste entre lo que se espera que los parlamentarios sean capaces de hacer y el nivel de preparación que se les exige para acceder a un cargo representativo, lo que a su vez convierte a la limitación de mandatos en un lujo inasequible para quienes se supone más deberían de beneficiarse de la misma. La tesis de que dicha inexperiencia podría superarse multiplicando el habitual recurso al personal de apoyo — jefes de gabinete, asesores, estrategas, expertos en comunicación - podría tal vez ser cierta, pero no lo sería menos que su uso generaría automáticamente tres problemas más: el de su repercusión sobre el erario público, el de la falta de independencia de unos parlamentarios excesivamente dependientes de su entorno, y el de la ruptura efectiva de la relación representativa, que pasaría a ser ejercida de facto por unos expertos carentes de toda legitimidad democrática.

En ese sentido - y ya trascendiendo el plano de la especulación teórica para adentrarse en el de los datos fácticos_- existen estudios que prueban que la implantación de la limitación de mandatos en legislativos como el del Estado de California ha traído como consecuencia una pérdida de influencia de los legisladores en la tarea presupuestaria ${ }^{49}$; al tiempo que destacan que la inexperiencia de los legisladores noveles ha repercutido en su menor eficacia a la hora de controlar la actuación del ejecutivo ${ }^{50}$; constatan un descenso de la producción legislativa del legislativo, debido a la ralentización de su actividad en comparación

49 Kurtz, K.; Cain, B.; Niemi, R., Institutional Change in American Politics: The case of Term Limits, University of Michigan Press, Ann Arbor, MI, 2009, p. 185.

50 CaIn, B. E., Adapting to Term Limits: Recent Experiences and New Directions, Public Policy Institute of California, San Francisco, CA., 2004, pp. 87 y 99. 
con la época anterior a la vigencia de las limitaciones de mandatos ${ }^{51}$; o acreditan una debilitación del liderazgo de los portavoces parlamentarios por su menor experiencia en las lides de la Cámara, que ha supuesto una alteración en el equilibrio entre los poderes que se ha desnivelado en favor del ejecutivo ${ }^{52}$. Por si ello no bastare, también se ha apuntado un dato que consideramos muy llamativo, por contradecir de plano la tesis de que la limitación de mandatos es útil para combatir la pervivencia de redes clientelares y las influencias espurias en la labor de los legisladores; y es que según estos autores, los lobbies y grupos de intereses mantienen e incluso acrecientan su influencia entre los miembros mas noveles de los parlamentos donde ahora rigen terms limits $^{53}$.

\subsection{La idoneidad de la limitación de mandatos para el logro de los objetivos propuestos}

Incluso si diéramos por buenas las dos afirmaciones sobre las que suelen asentar sus tesis los proponentes de la limitación de mandatos — la de que la clase política española se halla asediada por la corrupción, y la de que la periódica renovación de sus integrantes contribuiría a paliarla- sería todavía necesario demostrar que la regulación normativa de la limitación de mandatos constituiría un medio idóneo —o al menos útil— para lograr la deseada renovación de las elites y la necesaria erradicación de la corrupción política. Pero de nuevo nos hallamos ante una tesis que aun resultando a simple vista muy plausible, no lo es tanto una vez sometida a un análisis más sosegado.

Para empezar, resulta llamativo que cuando se reclama la implantación de medidas para limitar los mandatos éstas queden de ordinario circunscritas a los Presidentes del Gobierno —o, en su caso, de los gobiernos autonómicos—, con mucha menos frecuencia se extiendan a los parlamentarios, y muy rara vez se propongan en relación con los llamados «segundo» y «tercer escalón» de gobierno (es decir: ministros y secretarios de Estado, por un lado, y consejeros y secretarios autonómicos por otro). La idea de que impedir la perpetuación en el poder del Presidente del Gobierno o de la Comunidad Autónoma, permitiendo en cambio la de sus ministros o consejeros, vaya a ser útil en la lucha contra la corrupción nos parece cuando menos discutible, dado que la experiencia demues-

51 Clucas, R., «California: The new amateur politics», en R. FARMER, J. D. Rausch Jr., y J. C. Green. The Test of Time. Coping with Legislative Term Limits, Lexington Books, 2003, p. 25.

52 Caress, S. y Kunioka, T. Term limits and Their Consequences: The Aftermath of Legislative Reform, SUNY Press, Ithaca, NY, 2012, p. 92 y ss.

53 Kurtz, K.; Cain, B.; Niemi, R., op. cit., p. 185. 
tra que es precisamente en esos niveles inferiores del gobierno — a los que acceden personajes de menor proyección pública, menos carismáticos, y carentes del refrendo directo de las urnas- donde con más recurrencia hallamos casos de corrupción. De manera que si lo que se pretende es que los gestores públicos no acaben transformados en una oligarquía alejada de las verdaderas realidades y demandas sociales, la limitación de mandatos debería extenderse también a los llamados «segundo»y «tercer escalón» de gobierno. Solo que de hacerse así, es probable que la efectividad y la continuidad de la labor de gobierno quedara resentida hasta más allá de lo tolerable.

En esta misma línea, hay quien ha argumentado que la limitación de mandatos sería poco útil si no viniera acompañada de igualmente complejo sistema de veto a la rotación entre diferentes cargos públicos. A este respecto, IbáñezMacías ha sugerido la necesidad de «establecer una limitación de mandatos consecutiva pero total, es decir, para todo cargo público electivo: mediante la cual, el afectado, una vez que llevara un tiempo (uno o dos mandatos) ocupando uno o más cargos electivos, fueran cuales fueran éstos, debería dejar la política y volver a su actividad privada por un tiempo estipulado (uno o dos mandatos) antes de volver a postularse para cualquier cargo público electivo» ${ }^{54}$. Una mera limitación de las reelecciones en los cargos públicos sin la prohibición de rotación entre diferentes instituciones del Estado correría el riesgo de generar una pintoresca deambulación de políticos, desde una a otra institución, pero — de nuevo- es probable que poniendo en práctica esta medida la efectividad y la continuidad de la labor de gobierno no quedara resentida hasta más allá de lo tolerable, sino anulada por entero.

En tercer lugar tampoco falta quienes hayan planteado la necesidad de limitar la posibilidad de que los cargos públicos opten a la terminación de sus mandatos por acceder a puestos dirigentes en el mundo empresarial (las llamadas «puertas giratorias», por utilizar de nuevo una expresión de muy reciente incorporación a nuestro léxico político). En efecto, la tentación de favorecer determinados intereses empresariales a cambio de compensaciones económicas ilícitas puede perfectamente materializarse con la expectativa de que esa recompensa sea percibida no durante, sino a la conclusión de su mandato, y no en efectivo sino en forma de empleo o más frecuentemente de acceso a los consejos de administración de grandes empresas sin que a los beneficiarios de esta medida se les conozcan pericias reseñables en ninguno de los sectores de la economía cubiertos por las mismas. Además de prevenir y evitar tratos de favor a particulares durante el ejercicio del cargo la prohibición de estas «puertas giratorias» daría a la

54 IвÁÑEZ-MaCías, A., op. cit., p. 368. 
función política un aura de ejemplaridad que en principio parece altamente conveniente. El problema radica en que dicha prohibición combinada con la propia limitación de mandatos, acabara generando un efecto disuasorio: si el paso por la política va a ser necesariamente breve, y a su conclusión las posibilidades de empleo del ya ex alto cargo van a quedar sensiblemente mermadas, sobre todo en el ámbito laboral del que es experto ¿qué sentido tendría dar efectivamente el salto a lo público?

Por último, es imposible no percatarse de que en el sistema político español — como en tantos otros_ - las más de las veces es la posición de liderazgo en el partido la que facilita el acceso al cargo público y no a la inversa, y —-más todavía - la que determina la línea política a seguir; de manera que cualquier intento de controlar el acceso a estos últimos sin ocuparse de quién, cómo y durante cuanto tiempo detenta los primeros está llamada a tener unos limitadísimos efectos. Ferrajoli, por ejemplo, se ha posicionado decididamente por esta opción al proponer «la incompatibilidad entre cargos de partido y cargos públicos electivos, con el objeto de impedir el interés personal de los titulares de los primeros de auto-elegirse como titulares de los segundos» ${ }^{55}$. Tal vez esta última fórmula aportaría mayor salubridad al sistema político en su conjunto al equilibrar los poderes de partidos e instituciones, pero bien podría ser que generase el efecto perverso de que, al seguir los integrantes de estas últimas las instrucciones de los líderes de aquéllos, los ciudadanos acabaran representados por parlamentarios sin poder real y gobernados por líderes partidistas no electos ${ }^{56}$. Sea como sea lo cierto es que — como sentencia Eloy García— «la irrelegibilidad como figura jurídica gestada en el constitucionalismo de los individuos encuentra muy difícil acogida en el Estado de los partidos» ${ }^{57}$.

55 Ferrajoli, L., Poderes salvajes. La crisis de la democracia constitucional, Trotta, Madrid, 2011, p. 92.

56 Se trata, en suma, de la misma perplejidad vehementemente expresada por GARCía FERNÁNDEZ, J., pp. cit.: «La [...] pregunta es si está justificado limitar la reelección de solo el Presidente del Gobierno o no habría que limitar también la reelección de los parlamentarios y poner una duración determinada a los Ministros. ¿Sólo a los Diputados, Senadores y Ministros? ¿Y por qué no también a los Secretarios de Estado, Secretarios Generales y Directores Generales de los Ministerios? ¿Sólo en el ámbito del Estado y de su Administración General? ¿No habría que implantar límites en las Comunidades Autónomas y en las Entidades Locales? Porque no parece sensato poner límites a los Presidentes del Gobierno y no hacerlo a Alcaldes, Concejales, Presidentes y Diputados autonómicos y Diputados y Senadores. Y siguiendo ese razonamiento, ¿está justificado poner límites temporales a los políticos y no los miembros de los consejos de administración y demás directivos de las sociedades participadas presentes en el IBEX?».

57 García López, E., op. cit., p. 20. 
Así las cosas quizás no estuviera de más apuntar hacia caminos enteramente distintos para alcanzar el objetivo que dicen defender los partidarios de la limitación de mandatos. Si se quiere atajar las tentaciones autoritarias, o de enriquecimiento ilícito de las élites políticas, ¿por qué no introducir la revocación de los cargos electos, mediante la oportuna apelación a la participación popular, en los términos ensayados por algunos países latinoamericanos, o en otros distintos? O mejor aun, y sin necesidad de complejizar aun más nuestro sistema institucional ¿por qué no reforzar los mecanismos de fiscalización parlamentaria, o la dotación material y personal del poder judicial?

\section{4. ¿SERÍA CONSTITUCIONAL INTRODUCIR LA LIMITACIÓN DE MANDATOS EN ESPAÑA?}

Discutida la oportunidad de introducir el instituto de la limitación de mandatos en nuestro ordenamiento jurídico y su idoneidad como instrumento para la resolución de los problemas para cuyo abordaje se plantea, quedaría por encarar la nada baladí cuestión de su compatibilidad con ese mismo ordenamiento jurídico.

A nuestro parecer, ese interrogante resulta susceptible de segmentarse en otros tres, de modo que nos preguntaremos sucesivamente acerca de (a) cual habría de ser el rango de la norma que introdujera la limitación de mandatos en nuestro sistema o, más específicamente, si ésta podría ser introducida por medio de una reforma legislativa o precisaría emprenderse una reforma de la Constitución; (b) si su introducción entraría en colisión con alguno de los derechos fundamentales reconocidos en nuestra ley fundamental y (c) si el instituto de la limitación de mandatos sería a la postre compatible con el diseño global del sistema político español y, en particular, con la opción del constituyente por una monarquía parlamentaria.

\subsection{La cuestión del rango normativo: ¿sería precisa una reforma constitucional?}

Como hemos tenido la oportunidad de comprobar, el abordaje de la cuestión a nivel autonómico ha estado lejos de saldarse con una solución uniforme. Si en Castilla-La Mancha, Extremadura y Murcia la limitación de mandatos — circunscrita exclusivamente al presidente autonómico - se introdujo merced a una simple reforma de la correspondiente Ley de Gobierno, en Cataluña se creyó conveniente su previa autorización estatutaria (ayuna sin embargo de desarrollo normativo), y en Andalucía se objetó precisamente la falta de esa autorización 
como impedimento insalvable a la hora de introducirla mediante una reforma legislativa, siendo todavía incierto el desenlace que la cuestión vaya a tener en Madrid.

Por lo que hace a la doctrina, las posturas resultan exactamente igual de encontradas $^{58}$, de manera que mientras que Pérez Royo considera discutible romper con una tradición democrática consolidada sin al menos llevar a cabo una reforma del correspondiente estatuto de autonomía e Ibáñez-Macías ${ }^{59}$ va incluso más lejos al exigir no solo autorización estatutaria, sino también coherencia entre la ley electoral autonómica y las disposiciones generales de la LOREG en materia de inelegibilidad; María Antonia Trujillo entendió — en el caso concreto de la reforma extremeña - que con la introducción de la limitación de mandatos se estaba cubriendo «un déficit en la legislación autonómica» y avanzando «en la regeneración democrática»; mientras que Juan Antonio Doncel juzgó que la articulación material mediante Ley ordinaria aprobada por mayoría simple era, sencillamente, «poco relevante».

Lejos de pertenecer al ámbito de la mera técnica legislativa, la cuestión reviste tanto en el plano autonómico como en el estatal una extraordinaria importancia dogmática y una trascendencia política no menos decisiva. De manera que, situados ante la eventual decisión de introducir en España las limitaciones que venimos analizando, ¿qué texto normativo habría de ser reformado a tal efecto? La pregunta admite distintas respuestas, pero éstas básicamente nos remiten a una disyuntiva básica: la de si nos hallamos ante una reforma que por afectar a los derechos fundamentales de los españoles, o a algún aspecto sustancial del sistema político diseñado en la Constitución, precisaría para su introducción de una reforma constitucional; o si por el contrario nos hallamos ante una modificación de detalle de nuestro sistema electoral, o del estatuto del Presidente del Gobierno, que podría ser introducida mediante una simple reforma legislativa.

En efecto, quien considere la materia sobre la que operar como elemento puramente adjetivo, bien sea de los procesos electorales, bien sea de las condiciones para la conformación del Gobierno, se dará por satisfecho modificando la Ley 5/1985, de 19 de junio, de Régimen Electoral General, para la introducción de límites a la elección de los parlamentarios, o la 50/1997, de 27 de noviembre, del Gobierno, para hacer lo propio respecto del Presidente del Gobierno. Desde esta perspectiva, para conseguir lo primero debería bastar con añadir al listado

58 Fernández, M., «Monago fija en Extremadura por ley la primera limitación de mandatos» en El País, de 04.112013 (en línea en http://politica.elpais.com/politica/2013/11/04/actualidad/1383564767_832361.html)

59 IвÁÑEZ-MaCías, A., op. cit., p. 384. 
de causas de inelegibilidad que enumera el artículo sexto de la Ley Orgánica 5/1985 una más - la de haber desempeñado el cargo de diputado o de senador durante un determinado número de años, o de legislaturas-; al tiempo que lo segundo se podría conseguir añadiendo una cláusula semejante a la anterior en la Ley $50 / 1997^{60}$.

Por el contrario, quien entienda que la introducción de un límite en los mandatos está a su vez limitando o matizando los derechos constitucionales a la participación política por medio de representantes y al sufragio pasivo (arts. 23.1 y 23.2 CE), o alterando sustancialmente el sistema de gobierno diseñado por el constituyente, necesariamente habrá de abogar por la reforma previa de la propia Constitución.

Llegados a este punto, nuestro análisis debe distinguir entre las dos hipótesis que hemos venido analizando hasta el momento. Por lo que respecta al establecimiento de una limitación de mandatos en el poder legislativo es menester recordar que la Constitución, en su artículo 70.1 establece que será la ley electoral la que «determinará las causas de inelegibilidad e incompatibilidad de los Diputados y Senadores». La Ley Fundamental contiene pues una remisión normativa a la ley para la determinación de qué circunstancias podrían ser susceptibles de limitar el sufragio pasivo de un ciudadano en pleno uso de sus derechos, lo que empuja a pensar que debería bastar con la inclusión entre las causas de inelegibilidad que enumera el artículo sexto de la Ley Electoral la de haber desempeñado el cargo de diputado o de senador durante un determinado número legislaturas, consecutivas o alternas, o durante un determinado número de años, con o sin un periodo de cadencia. El argumento nos parece poderoso; puesto que si la propia Constitución admite explícitamente la posibilidad de restringir los derechos fundamentales de su artículo 23 y, simultáneamente, remite a la ley orgánica posterior para que allí se regulen la cuestión, nada debería impedir que así sucediera si el legislador lo considerara oportuno. En esta misma línea abunda la STC 45/1983, la cual en su FJ 6. ${ }^{\circ}$ establece que:

«El artículo 23.2 de la CE consagra el derecho del ciudadano a acceder en condiciones de igualdad a las funciones y cargos públicos, con los requisitos que señalen las Leyes. La elegibilidad es a tenor del artículo 70.1 de la CE un derecho ciudadano configurado por las leyes y delimitado negativamente por la ausencia de causas de inelegibilidad, que se inserta en el marco del artículo 23.2, de modo

60 Propósito éste de más difícil cumplimiento que el anterior, toda vez que la Ley 50/1997 se limita a enumerar las competencias del Presidente del Gobierno (así como las de los Vicepresidentes y los Ministros) sin contener una sola disposición relativa al modo de designación de éste sobre la cual pudiera superponerse la limitación de mandatos. 
que, desde este parámetro, no podrá negarse a quien, estando en el pleno uso de sus derechos políticos, no esté incurso en causas de inelegibilidad, definidas en la C. E. y por remisión, en la Ley Electoral, interpretadas dentro del marco constitucional.» 61

Con todo, de optarse por esta fórmula subsistiría el problema de la efectividad real de la norma. Para la reforma de una ley orgánica basta, como es sabido, su aprobación por mayoría absoluta del Pleno del Congreso, de modo que la introducción por esta vía de la institución de la limitación de mandatos podría fácilmente ser revertida por el voto de una mayoría parlamentaria de signo contrario en una legislatura posterior — máxime cuando resulta perfectamente posible determinar con años de anticipación cuándo y sobre quienes se proyectarían los efectos de la limitación de mandatos-, con lo que la limitación dejaría de ser en puridad tal. La objeción es de peso suficiente como para hacer aconsejable la previa reforma del artículo $70 \mathrm{CE}$ por las vías previstas en la propia Constitución — que entre otros requisitos exigen una mayoría parlamentaria cualificada-, con el objetivo de hacer perdurable la modificación y conseguir estabilidad institucional.

Por lo que respecta al establecimiento de una fórmula para limitar la reelección del Presidente del Gobierno, el análisis del texto constitucional revela que a diferencia de lo que sucede con las causas de inelegibilidad de los diputados y los senadores, la Constitución no solo no contempla respecto del Presidente del Gobierno una remisión semejante a la ley — no lo es en modo alguno la del artículo 98.4 CE que se refiere al «estatuto e incompatibilidades de los miembros del Gobierno»—, sino que además contiene en su articulado un detallado procedimiento para la selección del candidato a presidir el Gobierno que deja escaso margen al legislador para operar sobre él de manera restrictiva; más todavía cuando resulta que su desarrollo se lleva a cabo por el Reglamento del Congreso.

Y por si ello no bastare, la dicción del artículo 99.1, en el que se afirma que

«Después de cada renovación del Congreso de los Diputados, y en los demás supuestos constitucionales en que así proceda, el Rey, previa consulta con los representantes designados por los grupos políticos con representación parlamentaria, y a través del Presidente del Congreso, propondrá un candidato a la Presidencia del Gobierno.»

En ningún momento contempla causas que inhabiliten para el acceso a la jefatura del Ejecutivo, ni limita la libertad del Rey para proponer ni de los grupos parlamentarios para sugerir eventuales candidatos. No cabe sino concluir

${ }^{61}$ STC n. ${ }^{\circ} 45 / 1983\left(\right.$ Sala $\left.2 .^{a}\right)$ de, 25.05.1983. 
que el constituyente, que se desentendió de las causas de inelegibilidad de los parlamentarios, buscó en cambio abrir al máximo el abanico de posibilidades del Rey y del Congreso para conformar un gobierno estable, de modo que renunció a contemplar la necesidad de ser diputado para poder ser elegido como Presidente del Gobierno - lo que, por cierto, obliga a descartar la posibilidad de que limitando los mandatos de los legisladores pudiéramos indirectamente limitar el de los Presidentes_ — ${ }^{62}$, o de exigir que el candidato propuesto perteneciera al grupo parlamentario más numeroso ${ }^{63}$. Así las cosas, ¿cómo sería posible prohibir por ley lo que la Constitución permite? ¿O interpretar el clamoroso silencio sobre los requisitos para ser elegido Presidente del Gobierno del artículo 99.1 en comparación con el 70.1 sin recordar el brocardo clásico ubi lex non distinguit nec nos distinguere debemus? ${ }^{64}$.

\subsection{La colisión con los derechos constitucionales y con el propio principio democrático}

La determinación del rango que debería poseer la norma que introdujera en España la limitación de mandatos se halla en estrecha dependencia respecto de la cuestión de si ésta práctica podría entenderse limitativa de algún derecho o conculcadora de algún principio constitucional, ya que como es obvio en caso de responder afirmativamente a esa pregunta la reforma constitucional quedaría como única opción viable, e incluso debería practicarse en el doble frente de la tabla de derechos del Título I, y de la configuración de las instituciones legislativa y ejecutiva de los Títulos III y IV.

62 Sensu contrario, IBÁÑEZ-Macías, A. (op. cit., p. 371) contempla la introducción de esta exigencia -que el 152.1 CE impone respecto de ordenamientos autonómicos, y el 196 de la LOREG respecto de los ayuntamientos - para resolver el problema de la limitación de mandatos del Presidente del Gobierno por el sencillo método de por un lado exigirle la condición de parlamentario, y por otro limitar la reelección de éstos.

63 En ese sentido, vid. García Fernández, J., op. cit.

64 Obvio es decirlo, este criterio no está ayuno de consecuencias políticas relevantes. Si la introducción de la limitación de mandatos del Presidente del Gobierno fuera susceptible de materializarse a través de una reforma legislativa, la misma podría ser introducida al margen de la voluntad del partido gobernante, aunque fuera al precio de un muy probable recurso de inconstitucionalidad. Pero en cambio no podría serlo en modo alguno si fuera menester una reforma constitucional, habida cuenta de la mayoría absoluta que éste ostenta en la cámara alta. Pero dado que es difícil de imaginar que la limitación de mandatos fuese el único asunto sobre el que tratase una eventual reforma de la Constitución, sino que parecería más plausible contemplarla como un asunto colateral dentro de un acuerdo reformador mucho más amplio, la necesidad de materializarla a través de una reforma constitucional probablemente suponga su efectiva postergación hasta que el consenso necesario sobre la materias más candentes haya sido alcanzado. 
Pero en este plano resulta difícil mantener una opinión distinta de la que sustenta Ibáñez-Macías ${ }^{65}$ :

«El elector no tiene un derecho ilimitado a elegir a quien quiera como parlamentario. Sólo podrá elegir entre aquellos candidatos que hayan presentado su candidatura de acuerdo con la legislación electoral. Y uno de los requisitos para presentarse como candidato es no incurrir en causa de inelegibilidad. La limitación de mandatos se configuraría en nuestro país como una causa de inelegibilidad.»

Desde la perspectiva del sufragio activo, resulta la única conclusión posible a la vista del encaje entre el 23.1 CE — que proclama el derecho de los ciudadanos «a participar en los asuntos públicos, directamente o por medio de representantes, libremente elegidos en elecciones periódicas por sufragio universal»- y el ya mencionado artículo 70.1 CE que remite a la ley para determinar «las causas de inelegibilidad e incompatibilidad de los Diputados y Senadores» ${ }^{66}$. Y lo es asimismo desde la perspectiva del sufragio pasivo, ya que el 23.2 hace depender el derecho a acceder en condiciones de igualdad a las funciones y cargos públicos de la satisfacción de «los requisitos que señalen las leyes» ${ }^{67}$. Y es además la única postura coherente con el hecho de que en nuestro país ese supuesto derecho del ciudadano «a elegir a quien quiera como parlamentario» se encuentre ya sometido a un sinnúmero de limitaciones, entre las que no son menores la reiterada utilización de listas bloqueadas y cerradas, el uso de procedimientos de elaboración de listas escasamente transparentes, y la limitada democracia interna de muchos partidos.

Cosa distinta sería, en cambio, afirmar que la limitación de mandatos casaría bien con el resto de las causas de inelegibilidad previstas por el referido artículo 6 de la LOREG en sus dos primeros párrafos. Una lectura sosegada de las mismas

65 IBÁÑEZ-MacíAs, A., op. cit., p. 382.

66 Sobre el que SolozÁBAL, J. J. («Las inelegibilidades e incompatibilidades de los diputados y senadores y el control judicial de las elecciones al Congreso y al Senado». Comentarios a la Constitución Española, Alzaga, O. (Coord.). Tomo VI, Edersa, Madrid, 2006, pp. 282-322) afirma que contiene «una reserva de ley específica. Ello significa que el constituyente atribuye la normación de una materia al legislador, no habilitándolo propiamente, sino imponiendo su intervención, de modo que sea la ley la que decida las cuestiones esenciales en la materia correspondiente. Como se sabe, en el ordenamiento español [... ] la reserva de ley no es una cláusula constitucional de apoderamiento de facultades normativas al legislador a quien se reconoce [...] una competencia universal de normación sobre todo tipo de materias, sino una cláusula en cuya virtud se impone necesariamente la regulación por ley en el ámbito material a que dicha reserva se refiere, prohibiéndose la intervención normativa -innovadora, no meramente complementaria- sobre tal ámbito material».

67 Es también la opinión de García Fernández, J., op. cit., para quien «desde el punto de vista subjetivo del candidato esa limitación no conculcaría el derecho fundamental a acceder a funciones y cargos públicos porque el artículo 23.2 contiene una remisión a los requisitos que establezcan las Leyes». 
permite colegir que todas las del párrafo primero son, sin excepción, restricciones a la elegibilidad de ciudadanos en pleno uso de sus derechos por razón del oficio o cargo público que se hallen desempeñando, de las que éste podría zafarse de manera inmediata con la simple renuncia al mismo - cosa que en cambio no sucedería de contemplarse como causa de inelegibilidad un dato tan absolutamente irreversible como el de haber desempeñado el cargo de diputado o de senador durante un determinado número legislaturas-. En cuanto a las causas del apartado segundo, bastará su lectura para concluir que sería un dislate añadir a éstas la condición de veterano miembro del parlamento. Más todavía: como apunta Eloy García ${ }^{68}$ habría incluso un radical divorcio entre sus respectivos fines. $Y$ es que «la posibilidad de incorporar la figura de la irreelegibilidad en un ordenamiento constitucional-liberal atribuyéndole los rasgos de la inelegibilidad, y subsumiéndola como una variante más en la misma» difícilmente puede realizarse «sin traicionar el sentido de la institución que, como se indicó, estriba en garantizar la libertad de sufragio activo».

Más discutible nos parece, por último, la tesis de que la limitación de mandatos parlamentarios supondría una garantía adicional de la libertad de ejercicio del derecho de sufragio activo, al evitar que la perpetuación de las mismas personas en el ejercicio del poder pueda dar lugar a una clase política cerrada que se aferre al poder mediante la confección de las lista electorales a su antojo e impida que otros ciudadanos alcancen el poder haciendo uso de las ventajas competitivas que el sistema político brinda a quienes ya se encuentran instalados en su interior. Como hemos argumentado reiteradamente, la dinámica de partidos hace que el simple relevo en los candidatos no tenga porque traer aparejada una renovación de las elites, y la existencia de un potente sistema de frenos y contrapesos hace que la reiterada presencia de un candidato en las listas electorales en modo alguno garantice su perpetuación en el cargo.

\subsection{El problemático encaje de la limitación de mandatos en un sistema parlamentario}

Según Serrafero ${ }^{69}$, el estudio de una institución determinada y concreta — v. gr. la posibilidad de reelección del jefe del Gobierno- no puede escindirse del conjunto institucional del país. Y ello porque:

«La posibilidad de reelección tiene que ver, entonces, con varios factores: la duración del cargo, la cantidad de poder que concentra el Ejecutivo y que puede

68 García López, E., op. cit., p. 19.

69 Serrafero, M., op. cit., pp. 226-227. 
ejercer efectivamente, la existencia o no de reales controles institucionales considerando los mecanismos de limitación del régimen constitucional y los del sistema político, las costumbres y tradiciones políticas de los partidos y sus líderes en cuanto a la alternancia en el poder o el deseo de continuismo.»

Efectivamente, proponer la introducción en un determinado país de instituciones gestadas y maduradas en otras latitudes haciendo abstracción de los valores consagrados en su constitución, del conjunto de su sistema de gobierno, de sus tradiciones políticas y — naturalmente- de sus carencias, constituye una ligereza que fácilmente podría incluso transmutarse en demagogia.

En el caso concreto de España, entre los factores históricos que no pueden ser ignorados se cuentan — cuando menos- el de que entre nosotros el peligro del autoritarismo se halla enteramente conjurado; y el de que la limitación de mandatos carece por completo de tradición. Y entre los factores institucionales que deben ser igualmente tomados en consideración se cuentan el de que en nuestro país existe un sistema parlamentario en donde nadie puede hacerse con el timón del Ejecutivo sin antes contar con la confianza de la cámara baja del Legislativo; que quien ostenta ese cargo está sometido al control permanente de ambas cámaras; que la institución de la moción de censura permite que en cualquier momento sea revocado en sede parlamentaria el mandato presidencial; que, incluso sin activar este último mecanismo, las cámaras pueden bloquear o entorpecer muy seriamente las eventuales extralimitaciones del Presidente merced a sus atribuciones legislativas y presupuestarias; y que España cuenta con un Tribunal Constitucional y un Poder Judicial razonablemente eficaces, independientes y celosos de sus atribuciones, listos para actuar ante cualquier indicio de criminalidad por su parte. Eso supone, por un lado, que resulte implausible vindicar el instituto de la limitación de mandatos como antídoto frente a una patología inexistente, pero — adicionalmente - que su introducción generaría importantes disfunciones en el funcionamiento del resto de nuestro sistema político.

Si lo primero no precisa mucha explicación, lo segundo quizás sí que las requiera.

Para empezar, la introducción en España de la limitación de mandatos del Presidente del Gobierno generaría un efecto diametralmente opuesto al que se pretende: y es que lejos de reducir el poder del ejecutivo, reduciría el del legislativo - y marginalmente, también el poder moderador del Jefe del Estadotoda vez que en un sistema parlamentario como el español es éste - en nuestro caso, su cámara baja - el que elige al Presidente del Gobierno a propuesta del Rey, y la limitación de mandatos implicaría una reducción — tal vez no muy 
relevante desde el punto de vista cuantitativo, pero si desde el cualitativolas opciones a disposición de una y otra institución ${ }^{70}$.

Pero adicionalmente, la efectiva aplicación de la limitación de mandatos toparía con no pocas dificultades, derivadas del hecho de que en nuestro sistema ni el mandato del presidente del Gobierno ni el de los parlamentarios tiene una duración fija, sino a lo sumo una duración máxima, susceptible de verse recortada en el primero de los casos por la interposición de una moción de censura o la perdida de una cuestión de confianza, y en el segundo por el recurso a la disolución anticipada de las cámaras. A diferencia de lo que sucede en los sistemas de corte presidencialista, en donde el mandato del Presidente y de las cámaras tiene — salvo que se recurra al impeachment - una duración precisa e inamovible, en los de corte parlamentario es imposible establecer a cuantos años equivale un «mandato» o a cuantos «mandatos» equivalen un determinado número de años. Lo que es susceptible de generar efectos perversos: por ejemplo, si limitásemos a dos los mandatos del Presidente —o de los parlamentarios- por considerar que ocho años resulta un tiempo suficiente para el desarrollo de sus tareas, una rápida sucesión de disoluciones anticipadas del legislativo podrían a la postre tener como consecuencia la imposibilidad de que unos u otros continuaran en el cargo después de apenas tres o cuatro años en él; mientras que si la limitación se calculase en años, una disolución anticipada — por cierto: decretada por el propio Presidente del Gobierno- de las cámaras antes de que se cumpliera el plazo máximo previsto en el cargo podría permitirle optar a un tercer mandato, burlando así el límite contemplado en la norma ${ }^{71}$. Y también de generar perplejidades: un Presidente elegido por el Congreso y censurado por éste a mitad de la

70 Yendo incluso más allá en el argumento, Nohlen, D. («XV. La reelección», en Nohlen, D.; Zovatto, D.; Orozco, J. y Thompson, J. (Comps.), Tratado de derecho electoral comparado de América Latina, Instituto Interamericano de Derechos Humanos, et al., México, 2007 , pp. 287-293, en p. 290), aduce incluso que «la no reelección restringe la capacidad del electorado de enjuiciar — positiva o negativamente- a los representantes», de modo que la introducción de la limitación de mandatos tendría el efecto de incrementar la irresponsabilidad del cargo público que no pudiera optar a la reelección, disminuyendo la capacidad de control (accountability) de sus electores. Fenómeno cuya incidencia sería en todo caso muy dispar en un sistema mayoritario en distrito uninominal y en uno proporcional y de lista. En el mismo sentido, García, E., op. cit., p. 7.

71 Adicionalmente, si el sistema contemplara un periodo de cadencia entre uno y otro mandato y este se hallara calculado en años — como sucede en la ley castellano-manchega, que exige el transcurso de un plazo de ocho años para optar a un nuevo mandato- cabría incluso otro tipo de perversión del instituto: el que se produciría si el presidente en el cargo disolviera anticipadamente el legislativo antes de que la legislatura en curso llegara a su término natural para cerrar el paso a un ex presidente de la Comunidad que estuviera aguardando el transcurso del plazo de cadencia para volver a optar al cargo. 
legislatura... ¿habría agotado uno de sus «mandatos», o solo parte de él? Un Presidente que permaneciera en funciones por la imposibilidad de elegir a su sustituto tras unas nuevas elecciones ¿estaría apurando su anterior «mandato» o haciendo uso ya el segundo? Cuántos «mandatos» estaría utilizando un Presidente que dimitiera a mediados de la legislatura y fuera de nuevo elegido dentro de esa misma legislatura? Y un parlamentario que renunciara a su escaño en los primeros días de la legislatura, como suele ser habitual, para ocupar un puesto de relevancia en la Administración ¿habría agotado uno de los «mandatos» permitidos por la ley?

\section{CONCLUSIONES}

Llegado el momento de extraer conclusiones de todo lo dicho hasta ahora, y con la intención declarada de no limitarnos a repetir de manera abreviada lo ya dicho sino a sintetizar las certezas que estimamos haber sido capaces de identificar, tres son las conclusiones que cabe formular.

La primera es que, pese a la indudable existencia en nuestro país de un clima de descontento social que ha identificado a la clase política con la corrupción y el privilegio, la idea de introducir en nuestro ordenamiento jurídico la limitación de mandatos, reiteradamente presentada como un eficaz antídoto frente a esos males, sigue siendo minoritaria. Lo es entre nuestras comunidades autónomas, de entre las cuales solo unas pocas se han aventurado por este camino, y solo en relación con el jefe de su ejecutivo; y lo es entre los partidos con representación parlamentaria, toda vez que solo «los de nuevo cuño» —Ciudadanos y Podemos - han apostado decididamente por ello, en tanto que los llamados «tradicionales» — PSOE y Partido Popular — parecen albergar dudas sobre el fondo y sobre la forma.

La segunda es que ninguna de las tres premisas sobre las que se sustenta la reivindicación de la limitación de mandatos parece corresponderse con la realidad. No es cierto que España padezca niveles alarmantes, y menos patológicos, de perpetuación en el poder de sus dirigentes — no ha sido el caso entre los Presidentes del Gobierno, apenas lo ha sido entre los autonómicos, y lo es solo limitadamente en el ámbito parlamentario-; no es cierto que haya una relación de causa efecto entre la sucesión de mandatos y la implicación en casos de corrupción; y, sobre todo, no esta probado que la instauración de la limitación de mandatos en los términos en los que usualmente es presentada, sea susceptible de terminar efectivamente con esas supuestas carencias de nuestra democracia. 
Y la tercera es que, en el caso de que se deseara acometer este objetivo, el mismo solo podría ser lícitamente alcanzado merced a una reforma de la Constitución. Aunque la limitación de los mandatos de los parlamentarios sería jurídicamente viable mediante una simple reforma de la Ley Electoral, a la que la propia Constitución se remite; en el caso de la limitación del mandato presidencial, que constituye en punto álgido de la cuestión, no existe margen alguno de maniobra que no pase por la reforma del artículo 98.1 CE. Cosa que habrá de tener una influencia determinante sobre la viabilidad de esta iniciativa, en la medida en que si su abordaje en sede legislativa podría llevarse a término sin el consenso del partido en el Gobierno —obvio es decirlo: el más concernido por las posibles consecuencias de la medida - la exigencia de una reforma constitucional convertiría automáticamente en necesario su concurso.

En suma, nos hallamos persuadidos de que el muy oportuno debate sobre la limitación de mandatos está sin embargo siendo acometido desde una perspectiva inadecuada, magnificando los problemas a los que se supone debería dar respuesta, dando por sentada su capacidad para resolverlos, simplificando su encaje normativo y, sobre todo, haciendo abstracción de las disfunciones que su instauración generaría en un sistema político distante en el tiempo, lejano en el espacio y distinto en sus premisas de aquel en el que la institución nació y arraigó.

Title:

The introduction of term limits in Spain: A critical approach.

Summary:

1. Some considerations on the topicality of the debate in Spain.

2. The changing reception of the limitation of mandates in comparative constitutionalism. 3. Would be useful introduce the limitation of mandates in Spain? 4. Would be constitutional introduce the limitation of mandates in Spain? 5. Conclusions.

\section{Resumen:}

Pese a que la Constitución española no contiene previsión alguna respecto a lo que coloquialmente conocemos ya como la limitación de mandatos, y a que tampoco hasta hoy ha considerado oportuno el legislador introducir en nuestro ordenamiento jurídico estatal este tipo 
de restricciones, lo cierto es que de un tiempo a esta parte la cuestión ha ido ganando gradualmente relevancia en el debate político, habiendo sido regulada ya en varias comunidades autónomas, siendo objeto de debate en otras, y figurando como parte del acuerdo político de investidura sobre el que se sustenta el actual Gobierno de la nación.

En este trabajo empezaremos pasando revista al estado de la cuestión en España, así como a los numerosos cambios constitucionales que a lo largo de las dos últimas décadas se han verificado a este respecto en los países latinoamericanos, marco tradicional de esta práctica; para acto seguido debatir en torno a la conveniencia y a la constitucionalidad de la introducción en España de la limitación de mandatos, en su doble dimensión: respecto de los miembros del legislativo, y respecto del responsable máximo del poder ejecutivo. En esta línea analizaremos con especial detalle la idoneidad del instituto para erradicar la corrupción y asegurar la renovación de las elites políticas, la adecuación del mismo a los perfiles netamente parlamentarios de nuestro sistema, y su compatibilidad con los derechos consagrados en nuestra Carta Magna.

\begin{abstract}
Despite the fact that the Spanish Constitution does not contain any provisions regarding what we colloquially know as term limits, nor has Parliament deemed it appropriate to introduce such restrictions in our legal system, the fact is that for some years now the issue has being gaining relevance in the Spanish political debate, having already been regulated in several autonomous communities, being discussed in others, and appearing as part of the political agreement on which the current Government of the nation is based.

In this paper we will begin by reviewing the state of the question in Spain, as well as the numerous constitutional amendments introduced in this respect in several Latin American countries - the traditional framework of this practice- during the last two decades; only to follow with the discussion of the convenience and the constitutionality of the introduction of term limits in Spain, in its twofold dimension: in relation to the members of the legislature and to the head of the executive branch. More specifically, we will pay close look to the suitability of the institute to eradicate corruption and ensure the renewal of political elites, to its adequacy to the declared parliamentary nature of our system, and to its compatibility with the rights enshrined in our Basic Law.
\end{abstract}


Palabras clave:

Limitación de mandatos, reforma constitucional, parlamento, gobierno, derecho de participación política.

Key words:

Term limits, constitutional reform, parliament, government, right to political participation. 